Provided for non-commercial research and education use. Not for reproduction, distribution or commercial use.

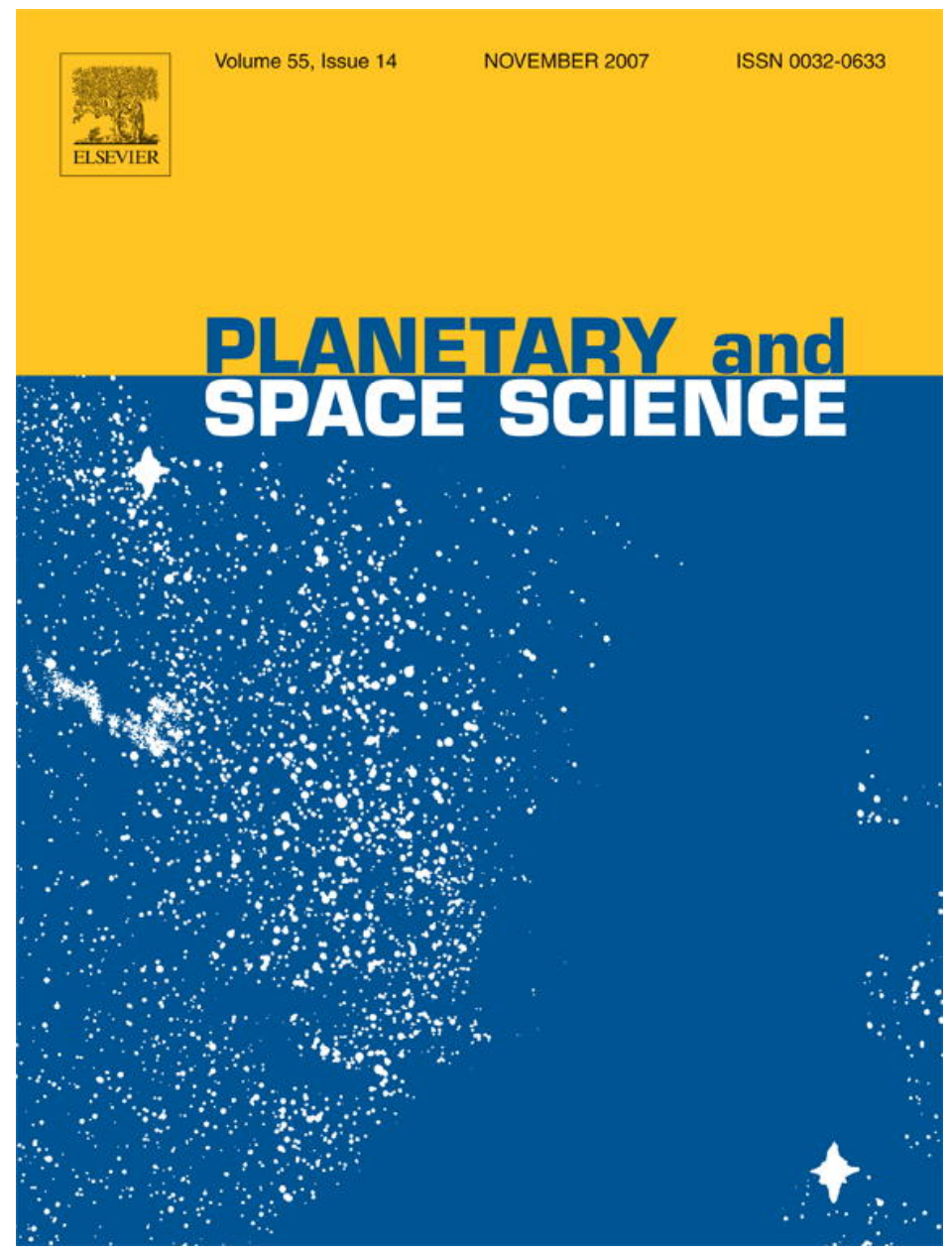

This article was published in an Elsevier journal. The attached copy

is furnished to the author for non-commercial research and education use, including for instruction at the author's institution, sharing with colleagues and providing to institution administration.

Other uses, including reproduction and distribution, or selling or licensing copies, or posting to personal, institutional or third party websites are prohibited.

In most cases authors are permitted to post their version of the article (e.g. in Word or Tex form) to their personal website or institutional repository. Authors requiring further information regarding Elsevier's archiving and manuscript policies are encouraged to visit: 


\title{
Evaluating planetary digital terrain models-The HRSC DTM test
}

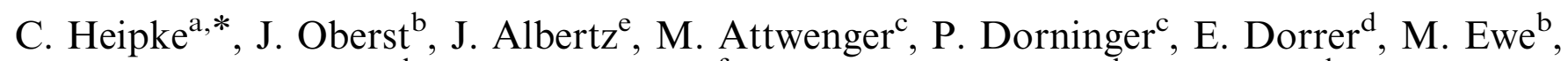
S. Gehrke ${ }^{\mathrm{e}}$, K. Gwinner ${ }^{\mathrm{b}}$, H. Hirschmüller ${ }^{\mathrm{f}}$, J.R. Kim ${ }^{\mathrm{g}}$, R.L. Kirk ${ }^{\mathrm{h}}$, H. Mayer ${ }^{\mathrm{d}}$, J.-P. Muller ${ }^{\mathrm{g}}$,

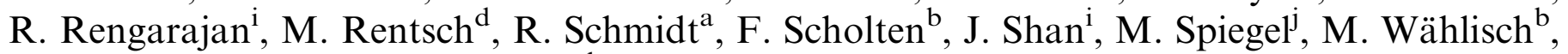
G. Neukum ${ }^{\mathrm{k}}$, the HRSC Co-Investigator Team

\author{
${ }^{a}$ Institute of Photogrammetry and GeoInformation (IPI), Leibniz Universität Hannover, Nienburger Str. 1, D-30167 Hannover, Germany \\ ${ }^{\mathrm{b}}$ Institute of Planetary Research, German Aerospace Center (DLR), Rutherfordstrasse 2, D-12489 Berlin, Germany \\ ${ }^{\mathrm{c}}$ Institute of Photogrammetry and Remote Sensing (IPF), Vienna University of Technology, Gusshausstrasse 27-29/E122, A-1040 Wien, Austria \\ ${ }^{\mathrm{d}}$ Institute for Photogrammetry and Cartography, Munich Bundeswehr University, 85577 Neubiberg, Germany \\ ${ }^{\mathrm{e}}$ Institute for Geodesy and Geoinformation Science, Technische Universität Berlin, Sek. H 12, Straße des 17, Juni 135, Berlin 10623, Germany \\ ${ }^{\mathrm{f}}$ Institute of Robotics and Mechatronic, German Aerospace Center (DLR), Oberpfaffenhofen, 82234 Wessling, Germany \\ ${ }^{\mathrm{g}}$ Department of Space and Climate Physics, University College London (UCL), Gower Street, London WC1E 6BT, UK \\ ${ }^{\mathrm{h}}$ Astrogeology Team, United States Geological Survey (USGS), 2255 N Gemini Drive, Flagstaff, AZ 86001, USA \\ ${ }^{\mathrm{i}}$ Geomatics Engineering, Purdue University, West Lafayette, IN 47907, USA \\ ${ }^{\mathrm{j}}$ Photogrammetry and Remote Sensing, Technische Universität München, Arcisstr. 21, 80333 München, Germany \\ ${ }^{\mathrm{k}}$ Institute of Geological Sciences/Planetology, Freie Universität Berlin, Malteserstr. 74-100, 12249 Berlin, Germany
}

Received 14 May 2007; received in revised form 17 July 2007; accepted 19 July 2007

Available online 23 August 2007

\begin{abstract}
The High Resolution Stereo Camera (HRSC) has been orbiting the planet Mars since January 2004 onboard the European Space Agency (ESA) Mars Express mission and delivers imagery which is being used for topographic mapping of the planet. The HRSC team has conducted a systematic inter-comparison of different alternatives for the production of high resolution digital terrain models (DTMs) from the multi look HRSC push broom imagery. Based on carefully chosen test sites the test participants have produced DTMs which have been subsequently analysed in a quantitative and a qualitative manner. This paper reports on the results obtained in this test. (C) 2007 Elsevier Ltd. All rights reserved.
\end{abstract}

Keywords: HRSC; Mars; Surface reconstruction; DTM/DEM; Experimental test

\section{Introduction}

The High Resolution Stereo Camera (HRSC, Neukum et al., 2004) is part of the orbiter payload on the Mars Express (MEX) mission of the European Space Agency (ESA), orbiting the Red Planet in a highly elliptical orbit since January 2004. For the first time in planetary exploration, a camera system has especially been designed to meet the requirements of photogrammetry and cartography for mapping the complete surface of a planet (Albertz et al., 2005). For this purpose HRSC operates as a

\footnotetext{
${ }^{*}$ Corresponding author. Tel.: + 49511762 2482; fax: + 495117622483 .

E-mail address: heipke@ipi.uni-hannover.de (C. Heipke).
}

multi-line push broom scanning instrument with 9 CCD line detectors mounted in parallel in the focal plane of the camera. Data acquisition is achieved by five panchromatic channels under different observation angles and four colour channels. At periapsis the ground resolution of the nadir channel amounts to $12.5 \mathrm{~m}$, the stereo channels are typically operated at a $2 \times$ coarser resolution with the two photometry and the four colour channels at $4 \times$ or $8 \times$ coarser resolution. The data provided by HRSC are well suited for the automatic generation of digital terrain models (DTMs) and other 3D data products. Such products are of vital interest to planetary sciences. After initial plan to operate MEX for 2 years only, the mission is now running in its fourth year and is scheduled to operate at least until 
May 2009. Thus, the prospects for a complete topographic mapping of Mars by HRSC at very high resolution are very good, indeed.

Image matching is well researched and has been documented in the literature. In general, it is agreed that in "simple" terrain (sufficient grey value variation, not too rough terrain) and with adequate image acquisition geometry (similar flying height, similar direction of optical axes, known relative image rotation if any), very good results can be achieved by totally automated approaches: the matching completeness in these areas reaches $100 \%$, at a density of various pixels per DTM grid mesh, and the geometric accuracy is well below one pixel. Things start to be much more complicated if complex situations are faced, such as steep terrain, height discontinuities, occlusions, poor texture, shadows, atmospheric dust, clouds, increased image noise, compression artefacts etc., some of which are commonplace in HRSC images.

Nevertheless, automatic DTM generation from HRSC images by means of image matching has reached a very high level over the years. The systematic processing chain at DLR for producing preliminary DTMs with $200 \mathrm{~m}$ resolution (Scholten et al., 2005) runs well and is stable, and DLR is currently starting the systematic generation of DTMs at high resolution (Gwinner et al., 2007). In addition, several groups are able to produce DTMs using different approaches, or have developed alternative modules for parts of the DTM generation process (Albertz et al., 2005). Also, some of these groups are developing interesting shape-from-shading (SFS) techniques. In some cases, the approaches are experimental and are limited to small areas.

It is against this background that the desire was expressed to compare the individual approaches for deriving DTMs from HRSC images in order to assess their advantages and disadvantages. This paper reports on the results obtained in this test and discusses the potential, performance and quality of DTMs generated from HRSC images.

\section{Test goals and organisation}

For generating a DTM a number of different steps must be carried out. The principal ones are

- image pre-processing (an optional step comprising radiometric noise reduction and pre-rectification),

- image matching,

- generation of a 3D point cloud, and

- DTM interpolation onto a regular grid.

While it is interesting to study these steps in detail it was decided that this test would take a more general view and analyse only the resulting DTMs. The reason is that several of the approaches do not yield comparable intermediate products, and thus a detailed study was not deemed feasible. In addition, reports examining the individual steps of DTM generation can be found in the literature, albeit not necessarily for planetary images.

Key goals of the test were the reconstruction of fine details and the geometric accuracy of the DTMs. Fine detail is studied using a variety of qualitative assessments in small but representative areas, while geometric accuracy is analysed with respect to the Mars Orbiter Laser Altimeter (MOLA) DTM (Zuber et al., 1992; Smith et al., 2001). This DTM is the most consistent Mars DTM available to date. Note that the geometric analysis suffers from the lack of a reference data set with superior accuracy, mainly because the MOLA DTM does not have an adequate planimetric resolution. The quantitative results presented in this paper therefore relate to the differences between the HRSC DTM and MOLA DTM, and incorporate the inaccuracies inherent in both sources. In addition, many groups used MOLA information already as input for their procedures, ${ }^{1}$ complicating the use of MOLA as a geometric reference since an independent check is not possible any more. Nevertheless, such computations are useful, because differences in the results from participant to participant can be linked to the individually generated HRSC DTMs. All quality parameters were also related to operational aspects such as the computing effort of the applied method, and thus its applicability to generating DTMs of large areas (multiple orbits, potentially the whole HRSC data set).

The test was organised by the Photogrammetry and Cartography Working Group within the HRSC CoInvestigator team under the auspices of the ISPRS Working Group IV/7 on Extraterrestrial Mapping. The Institute of Photogrammetry and GeoInformation (IPI) of Leibniz Universität Hannover, and the Institute for Planetary Research of the German Aerospace Center (Deutsches Zentrum für Luft- und Raumfahrt, DLR), Berlin-Adlershof acted as pilot centres for the test. Based on commonly agreed test data sets, including image orientations refined by bundle adjustment, a total of eight groups have derived DTMs. The pilot centres then analysed the produced data. To our knowledge this is the first multi-site test for DTM generation from planetary imagery.

\section{Test data}

Two data sets were chosen for the test. These are the HRSC images h1235_0001, ${ }^{2}$ and a block of three adjacent

\footnotetext{
${ }^{1}$ MOLA is used as control information in the bundle adjustment, as a surface for pre-rectification prior to matching, for fitting results of individual strip DTMs and for filling holes resulting from matching blunders. The degree to which the participants made use of MOLA varies (see Section 4).

${ }^{2}$ The notation refers to the file name convention used in the HRSC experiment. Image h1235_0001 was acquired in orbit 1235. In this orbit the HRSC was switched on twice, resulting in images h1235_0000 and h1235_0001. The latter one was used in this study. The names of the Nanedi images follow the same convention. In the remainder of the paper only the orbit numbers are used to identify the images, since no ambiguity can arise. In all cases the so called "bested" version (i.e. the archival quality version) was provided to the participants.
} 
Table 1

Description of the test data

\begin{tabular}{llll}
\hline & & Candor Chasma & Nanedi Vallis \\
\hline HRSC orbit & & 1235 & $894 ; 905 ; 927$ \\
Ground resolution & Nadir & $21-32 \mathrm{~m}$ & $14-23 \mathrm{~m}$ \\
& Stereo (2) & $42-80 \mathrm{~m}$ & $28-55 \mathrm{~m}$ \\
& Photometry (2) & $84-146 \mathrm{~m}$ & $55-102 \mathrm{~m}$ \\
& Colour (R, G, B, NIR) & $168-306 \mathrm{~m}$ & $54-106 \mathrm{~m}$ \\
No. of lines of complete image (nadir) & & 74144 & $45272 ; 51136 ; 57856$ \\
Area covered by complete image & & $1987 \times 139 \mathrm{~km}^{2}$ & $885 \times 101 ; 936 \times 95 ; 976 \times 87 \mathrm{~km}{ }^{2}($ indiv. images) \\
& & 11000 & $880 \times 260 \mathrm{~km}^{2}(\mathrm{mosaic})$ \\
No. of lines of sub-area (nadir) & & $275 \times 150 \mathrm{~km}^{2}$ & $300 \times 93 ; 300 \times 90 ; 300 \times 82 \mathrm{~km}^{2}($ indiv. images) \\
Area covered by sub-area & & $300 \times 240 \mathrm{~km}^{2}(\mathrm{mosaic})$ \\
\end{tabular}
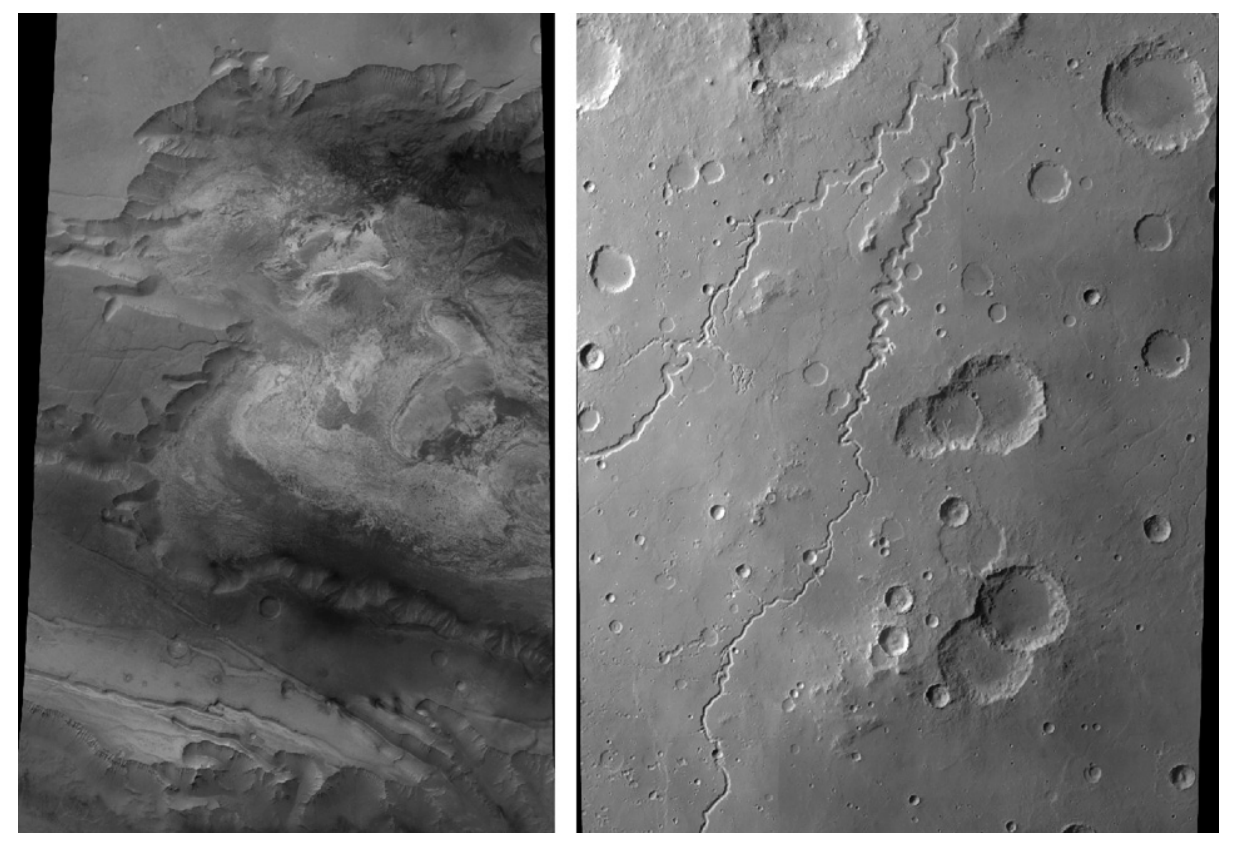

Fig. 1. Orthophotos of the sub-areas derived from the nadir channel: Candor Chasma (left, image h1235_0001), Nanedi Vallis (right, images h927_0000, h905_0000 and h894_0000 from left to right). Both images are oriented towards north.

images, numbered h0894_0000, h0905_0000 and h0927_0000² (see also Table 1). In addition to the processing of complete orbit images, sub-areas were defined for contributions of limited areas (Fig. 1). The sub-area in image 1235 covers western Candor Chasma at approximately $-8^{\circ} \mathrm{N}$ to $-4^{\circ} \mathrm{N}$ and $282-284^{\circ} \mathrm{E}$, and includes the spectrally distinctive Ceti Mensa. This sub-area exhibits many steep slopes and a number of horizontal plateaus with very little texture (see Fig. 1, left). The second sub-area covers Nanedi Vallis at approximately $2.5-7.5^{\circ} \mathrm{N}$ and $310-314^{\circ} \mathrm{E}$. In this area many craters of different size are visible (see Fig. 1, right). In addition to being scientifically interesting the Nanedi orbits provide a test of capabilities for producing seamless DTMs from blocks of images.

In general, the image quality of the Nanedi orbits is good, whereas the Candor Chasma image exhibits lower contrast and some image noise. While most image data were free of errors, all channels of image 927 contained gaps (areas for which no grey values had been recorded), most of them having a duration of less than $2 \mathrm{~s}$ (equivalent to 488 image lines). In addition, the backward stereo channel (stereo 2) contained a gap of $45 \mathrm{~s}$ corresponding to over 6000 image lines. Furthermore, the integration time was changed during image acquisition. ${ }^{3}$ Among other reasons this image was chosen in order to investigate how

\footnotetext{
${ }^{3}$ Changing integration times are used rather frequently in the HRSC experiment (not for image 1235, however). Due to the highly elliptical Mars Express orbit the ground resolution changes as a function of time. Whereas the across track pixel dimension on the ground cannot be influenced, the along track dimension is a function of the integration time. Changes in integration time thus allow for acquiring square pixels.
} 
Table 2

Overview of test participants, processed areas and used software

\begin{tabular}{|c|c|c|c|}
\hline Participant & & Processed area & Used software \\
\hline \multirow[t]{2}{*}{ DLR-Scholten } & V.1: standard & Complete orbits & $\begin{array}{l}\text { DLR approach for preliminary } \\
\text { DTMs, except for refined ext. ori. } \\
\text { par. and fit of strips to MOLA }\end{array}$ \\
\hline & $\begin{array}{l}\text { V.2: no noise reduction in images, no } \\
\text { post-filtering }\end{array}$ & & \\
\hline \multicolumn{2}{|l|}{ DLR-Scholten/UniBwM } & Nanedi sub-area & $\begin{array}{l}\text { DLR-Scholten V.1, refined by } \\
\text { shape-from-shading }\end{array}$ \\
\hline \multirow[t]{2}{*}{ DLR-Gwinner } & V.1: removal of blunders detected by IPF & Complete orbits & $\begin{array}{l}\text { V.2 is DLR approach for } \\
\text { systematic generation of high } \\
\text { resolution DTMs }\end{array}$ \\
\hline & V.2: no blunder detection by IPF & & \\
\hline DLR-Gwinner/IPF & 3D points from DLR-Gwinner as input & Complete orbits & $\begin{array}{l}\text { Self-developed blunder } \\
\text { detection }+ \text { SCOP }\end{array}$ \\
\hline \multirow{5}{*}{$\begin{array}{l}\text { DLR-Hirschmüller } \\
\text { Purdue } \\
\text { UCL } \\
\text { USGS }\end{array}$} & & Complete orbits & Self-developed \\
\hline & & Complete orbit (only Nanedi 905) & Self-developed \\
\hline & & Sub-areas & Self-developed \\
\hline & V.1: standard & Sub-areas (Nanedi 927 not processed) & $\begin{array}{l}\text { Semi-automatic approach } \\
\text { involving ISIS, SOCET SET and } \\
\text { some manual interaction }\end{array}$ \\
\hline & $\begin{array}{l}\text { V.2: refinement of V.1 results by shape- } \\
\text { from-shading }\end{array}$ & Candor sub-area & In addition to V.1 self-developed \\
\hline
\end{tabular}

For the abbreviations see list of authors and affiliations.

the individual matching approaches would cope with such challenges.

In addition to the images, orientation parameters were provided to the participants. The HRSC sensor model developed at DLR was used to describe the interior orientation. Exterior orientation parameters were derived from a bundle adjustment (Schmidt et al., 2005, 2006; Spiegel et al., 2005, 2006). Since the bundle adjustment uses MOLA data as control information, the resulting orientation parameters automatically tie the surface derived from image matching to the MOLA DTM. The theoretical standard deviation of the bundle adjustment for the complete orbits was about $25 \mathrm{~m}$ in planimetry (Candor and Nanedi), and $50 \mathrm{~m}$ (Candor) and $30 \mathrm{~m}$ (Nanedi) in height. The participants were encouraged to use these orientation parameters, but were free to determine their own interior and exterior image orientation parameters if they wished to do so.

All DTMs delivered back to the pilot centre were to be derived in the sinusoidal map projection based on centre latitude $\left(0^{\circ}\right.$ for both data sets) and longitudes agreed beforehand $\left(283^{\circ} \mathrm{E}\right.$ for Chandor Chasma and $311^{\circ} \mathrm{E}$ for Nanedi Vallis) using the MOLA sphere (radius: $3396 \mathrm{~km}$ ) as the lateral and vertical reference.

\section{Test participants and approaches used for generating DTMs}

Altogether eight groups agreed to participate in the test (see Table 2). Some of them delivered two sets of results, some processed the complete orbits, and others restricted their efforts to single orbits or sub-areas. The individual approaches are described in existing literature. Due to lack of space, only a short summary is provided here.

DLR-Scholten (Scholten et al., 2005): Image pre-processing consists of an optional box filtering (carried out in V.1, but not in V.2) and a pre-rectification of the images using the MOLA DTM. Least-squares image matching is done pairwise between the nadir channel and the four additional panchromatic channels (stereo and photometry). Point tuples are subsequently generated and $3 D$ points are computed by least squares forward intersection. A threshold for the intersection accuracy is applied to eliminate blunders. After interpolating the DTM, box filtering was employed to reduce artefacts (only in version 1). The deviation of the individual DTM strips to the MOLA DTM were then automatically analysed and adjusted based on piece-wise trend analysis.

DLR-Scholten/UniBwM (Dorrer et al., 2004, 2005): In this approach the DLR-Scholten V.1 DTM is refined through global SFS. The DTM interpolated to $50 \mathrm{~m}$ resolution, an orthophoto based on this DTM, the HRSC nadir channel and the sun vector field based on this DTM were provided by DLR. First, a "haze-gain" correction for the orthophoto radiometry was determined interactively. SFS is driven by least-squares minimisation of a functional consisting of two appropriately weighted, elevation-dependent terms, viz., irradiance term and height term. Assuming Lambertian reflectance and constant surface albedo, the developed SFS-method leads to an iterative refinement of 
the initial DTM. The SFS process was applied to the three Nanedi images separately and the resulting DTMs were then merged.

DLR-Gwinner (Gwinner et al., 2005, 2007): This contribution represents the approach to stereo matching and DTM interpolation adopted by DLR for the systematic generation of high-resolution DTM): Image pre-processing consists of space variant filtering and a prerectification of the images using the MOLA DTM (and the derived HRSC DTM for finer pyramid levels). Leastsquares image matching is done pairwise between the nadir channel and the four additional panchromatic channels (stereo and photometry). The size of the search window mimics an epipolar constraint. Point tuples are subsequently generated and $3 D$ points are computed by leastsquares forward intersection. In V.1 elimination of 3D blunders based on the procedure of DLR/Gwinner-IPF (see below) is performed, while in V.2 the original object points derived by least-squares forward intersection are used for DTM interpolation. DTMs are created by distance weighted raster interpolation from multiple object point sets derived at different matching scales. An integral part of this approach are standardised quality checks (e.g. point density and point accuracy depending on matching scale) which serve, e.g. for an appropriate selection of the DTM grid size.

DLR-Gwinner/IPF (Attwenger et al., 2005): This method uses the 3D points generated by DLR-Gwinner (see above) as input. Subsequently, a classification is carried out, which eliminates gross errors based on iterative linear prediction. Resulting holes were filled by interpolation. The positively classified data set was then returned to DLR (see DLRGwinner V.1). A DTM was also generated by IPF using the commercial DTM package SCOP; this result constitutes DLR-Gwinner/IPF.

DLR-Hirschmüller (Hirschmüller et al., 2005, 2006): Image pre-processing consists of a projection to a plane and a conversion of the radiometric resolution from 16 to 8 bits. Image matching is done pairwise between the nadir channel and all of the additional panchromatic channels (stereo and photometric) along epipolar lines. The nadir, the two stereo and the two photometry channels are used. Matching is driven by minimising a cost function involving mutual information (MI, Hirschmüller, 2005). MI is a measure based on the entropy of the two images and the mutual image entropy. Penalty terms are added to the cost function to support piecewise smoothness of the terrain. To reduce outliers matching is done in both directions (left $\rightarrow$ right, followed by right $\rightarrow$ left), the results from pairwise matching are fused in a robust manner, and peaks in the mean disparity map are removed. $3 D$ points for every pixel are then computed by forward intersection. Holes in the resulting DTM are filled using inverse distance weighted interpolation from the border of holes. Since the memory requirement of the procedure is relatively high processing was carried out in tiles. Finally a DTM with a reduced grid size was computed by the pilot centre.
The method had originally been developed for handling sharp depth discontinuities during matching as mainly occurring in terrestrial HRSC data of urban areas. The adaptation to Mars scenes consisted only in parameter tuning.

Purdue (Rengarajan et al., 2004): In this approach no image pre-processing is done. Image matching relies on a set of seed points (provided by the pilot centre). A crosscorrelation is first applied to refine the seed points and remove blunders. The selected seed points are then triangulated in image space based on a Delaunay triangulation. For each corresponding triangle pair a two-dimensional affine transformation is determined using the neighbouring seed points. A point with distinct feature properties within a triangle is then transformed into the second image and is considered as the candidate for matching. The actual corresponding point is found via cross-correlation followed by sub-pixel local maximum determination. This process runs iteratively until a desired point density is reached. Matching is done pairwise between the nadir channel and the two stereo channels. Cross-evaluation between the matching pairs is carried out to remove points with large inconsistence. Point tuples are subsequently generated and $3 D$ points are computed by least-squares forward intersection. A threshold for the intersection accuracy is applied to eliminate blunders. From these 3 D points a DTM was generated by the pilot centre. Finally, a $3 \times 3$ box filter was used to smooth the result. Only image 905 was processed.

UCL (Day et al., 1992; Kim, 2005): Image pre-processing consists of a pre-rectification of the images using the MOLA DTM. Image matching is based on automatically generated seed points. These were generated using software from DLR (upper third of Candor) and UCL (all other areas). Matching was carried out in pairs using the nadir and the two stereo strips. For those parts of image 927 without image information (see above) the nadir and the two photometry channels were used instead. The matching method employed was a variant of the adaptive least-squares correlation (ALSC, Grün, 1985), which is based on region-growing (Otto and Chau, 1989). The employed matching criterion is the maximum eigenvalue of the variance-covariance matrix of ALSC, which is minimised. Results of pairwise matching are then merged and $3 D$ points are computed via least-squares forward intersection. A threshold for the intersection accuracy is applied to minimise the number of blunders. Edge artefacts were cropped manually based on a visual inspection of the results. Finally, a DTM was interpolated from the results.

USGS (Kirk et al., 2003, 2006): Processing was done within the USGS digital cartographic system ISIS and the commercial SOCET SET system, Version 5.2 (Miller and Walker, 1993, 1995). Neither system is able to handle varying integration time within one orbit (this occurred for Nanedi, see above), neither can the exterior orientation parameters for the HRSC sensor be introduced as input. 
Therefore, separate image patches with constant integration time were generated for Nanedi by cutting up the image strips accordingly, and the exterior orientation was computed based on ground control points from MOLA tracks measured manually in the images (while for Candor the nadir, the two stereo and the four colour channels were included in the bundle adjustment, only the nadir and the stereo channels were employed for determining the exterior orientation of the Nanedi images). Image matching was done using SOCET SET's Adaptive Terrain Extraction module (ATE). The images were pre-rectified using the MOLA DTM. Matching was done in pairs between the nadir channel and stereo channels. The MOLA DTM was used as initial height values. The employed matching criterion is the cross-correlation coefficient. Point pairs are then transformed into 3D points by least-squares forward intersection, followed by DTM interpolation and merging of the individual DTMs. In this way two different DTMs with resolutions of 75 and $300 \mathrm{~m}$ were generated. Areas with blunders were identified interactively using stereo viewing in the $75 \mathrm{~m}$ DTMs and replaced by corresponding values of the $300 \mathrm{~m}$ DTM. In a second manual check remaining errors were corrected and in a number of flat areas of Candor MOLA values were substituted instead. Image 927 from Nanedi could not be processed in the described way. The reason for this is not understood, but it is probably not related to the missing image information in one of the stereo channels (see above) because the image gaps are filled with null data and affect only the placement of control points. A more likely explanation is that the problem relates to the greater roll angle of the 927 image compared to the others. For the Candor orbit the results were further refined using SFS (Kirk et al., 2006).

Key aspects of the individual matching approaches are summarised in Table 3 . Table 4 contains an overview of the DTM resolution selected by the participants together with a justification for this selection.

\section{Test results and evaluation}

In this section we report on the results obtained by analysing the data received from the participants. We have evaluated the DTMs generated by the participants from a global and a local point of view, looking either at the whole test area or at small but representative enlargements. In both cases quantitative and qualitative assessment has taken place.

In the quantitative assessment we compared the HRSC DTM to the MOLA data (for a justification see Section 2). The qualitative assessment consisted of a visual inspection of shaded relief representations of the derived DTMs, an investigation of the appropriate DTM resolution, an

Table 3

Key aspects of the individual matching algorithms

\begin{tabular}{|c|c|c|c|c|c|c|c|c|}
\hline Step & $\begin{array}{l}\text { DLR- } \\
\text { Scholten }\end{array}$ & $\begin{array}{l}\text { DLR-Schol- } \\
\text { ten/ } \\
\text { UniBwM }\end{array}$ & $\begin{array}{l}\text { DLR- } \\
\text { Gwinner }\end{array}$ & $\begin{array}{l}\text { DLR-Gwin- } \\
\text { ner/IPF }\end{array}$ & $\begin{array}{l}\text { DLR- } \\
\text { Hirsch- } \\
\text { müller }\end{array}$ & Purdue & UCL & USGS \\
\hline $\begin{array}{l}\text { Pre- } \\
\text { rectification }\end{array}$ & \multicolumn{2}{|c|}{ Yes, using MOLA DTM } & \multicolumn{2}{|c|}{$\begin{array}{l}\text { Yes, using MOLA and } \\
\text { preliminary HRSC DTM }\end{array}$} & $\begin{array}{l}\text { Yes, using a } \\
\text { plane }\end{array}$ & No & $\begin{array}{l}\text { Yes, using } \\
\text { MOLA } \\
\text { DTM }\end{array}$ & $\begin{array}{l}\text { Yes, using } \\
\text { affine } \\
\text { transform. }\end{array}$ \\
\hline $\begin{array}{l}\text { Reduction of } \\
\text { radiom. } \\
\text { noise }\end{array}$ & \multicolumn{2}{|c|}{ Yes (not for V.2) } & \multicolumn{2}{|l|}{ Yes } & No & No & No & No \\
\hline $\begin{array}{l}\text { Epipolar } \\
\text { constraint }\end{array}$ & \multicolumn{4}{|c|}{ Indirectly through form of search space } & Yes & No & No & $\begin{array}{l}\text { Indir. } \\
\text { through } \\
\text { form of } \\
\text { search space }\end{array}$ \\
\hline $\begin{array}{l}\text { Matching } \\
\text { method }\end{array}$ & \multicolumn{4}{|l|}{$\mathrm{LSM}^{\mathrm{a}}$} & $\begin{array}{l}\text { Mutual } \\
\text { information }\end{array}$ & $\begin{array}{l}\text { Cross- } \\
\text { correlation }\end{array}$ & $\mathrm{ALSC}^{\mathrm{b}}$ & $\begin{array}{l}\text { Cross- } \\
\text { correlation }\end{array}$ \\
\hline $\begin{array}{l}\text { No. of used } \\
\text { channels }\end{array}$ & \multicolumn{4}{|l|}{5} & 5 & 3 & 3 & 3 \\
\hline $\begin{array}{l}\text { Image } \\
\text { orientation }\end{array}$ & \multicolumn{7}{|c|}{ Standard HRSC sensor model and values derived from bundle adjustment with MOLA DTM as control information } & $\begin{array}{l}\text { Self- } \\
\text { determined }\end{array}$ \\
\hline $\begin{array}{l}\text { Constant set } \\
\text { of para- } \\
\text { meters }\end{array}$ & Yes & & No & & Yes & $\begin{array}{l}\text { Not } \\
\text { applicable }\end{array}$ & Yes & Yes \\
\hline $\begin{array}{l}\text { Human } \\
\text { interaction }^{\mathrm{c}}\end{array}$ & No & & No & No & No & No & $\begin{array}{l}\text { No, except } \\
\text { man. crop- } \\
\text { ping of edge } \\
\text { artef. }\end{array}$ & Yes \\
\hline
\end{tabular}

\footnotetext{
${ }^{\mathrm{a}} \mathrm{LSM}$-least squares matching.

${ }^{\mathrm{b}}$ ALSC-adaptive least squares correlation with region growing.

${ }^{\mathrm{c}}$ Other than test runs etc. to define process parameters.
} 
analysis of profiles along the MOLA tracks and in East/ West direction, an evaluation of height contours derived from the DTMs and superimposed to HRSC orthophotos, and a detection study of small craters in the DTMs. Finally, operational aspects were assessed. They are

Table 4

Deliverables of the participants

\begin{tabular}{|c|c|c|}
\hline Test participant & DTM resolution & $\begin{array}{l}\text { Remarks on selection of DTM } \\
\text { resolution }\end{array}$ \\
\hline DLR-Scholten & $200 \mathrm{~m}$ & Standard value \\
\hline $\begin{array}{l}\text { DLR-Scholten/ } \\
\text { UniBwM }\end{array}$ & $50 \mathrm{~m}$ & $\begin{array}{l}\text { Selection based on assumed } \\
\text { potential of the technique }\end{array}$ \\
\hline DLR-Gwinner & $\begin{array}{l}75 \mathrm{~m} \text {, except } \\
\text { image } 905 \text { and } \\
\text { Nanedi mosaic: } \\
50 \mathrm{~m}\end{array}$ & $\begin{array}{l}\text { Selection based on test runs for } \\
\text { point density and accuracy } \\
\text { depending on matching } \\
\text { resolution }\end{array}$ \\
\hline $\begin{array}{l}\text { DLR- Gwinner/ } \\
\text { IPF }\end{array}$ & $50 \mathrm{~m}$ & $\begin{array}{l}\text { Selection based on input data } \\
\text { density }\end{array}$ \\
\hline $\begin{array}{l}\text { DLR- } \\
\text { Hirschmüller }\end{array}$ & $50 \mathrm{~m}$ & $\begin{array}{l}\text { Grid size equivalent to image } \\
\text { resolution delivered: } 30 \mathrm{~m} \\
\text { (Candor) and } 15 \mathrm{~m} \text { (Nanedi), } \\
\text { computation of DTM by pilot } \\
\text { centre according to directions of } \\
\text { participant }\end{array}$ \\
\hline Purdue & $200 \mathrm{~m}$ & $\begin{array}{l}\text { 3D point cloud delivered, } \\
\text { computation of DTM by pilot } \\
\text { centre according to directions of } \\
\text { participant }\end{array}$ \\
\hline $\mathrm{UCL}$ & $\begin{array}{l}50 \mathrm{~m} \text { (Candor) } \\
25 \mathrm{~m} \text { (Nanedi) }\end{array}$ & $\begin{array}{l}\text { Based on visual inspection of } \\
\text { intermediate results }\end{array}$ \\
\hline USGS & $75 \mathrm{~m}$ & $\begin{array}{l}\text { DTM resolution }>\text { image } \\
\text { resolution of nadir channel } \times 3\end{array}$ \\
\hline
\end{tabular}

discussed with respect to the needed computational time and resources for generating the DTMs.

\subsection{Comparison to the MOLA}

In the first step we computed the offset (mean difference) and the standard deviation between the derived HRSC DTMs and the MOLA Mission Experiment Gridded Data Records (MEGDR), resolution 128 pixels/degree; Neumann et al., 2003. Rather than comparing surface heights in two dimensions we only compared height values from both DTMs at the lateral positions of original one dimensional MOLA tracks running through the test areas. Track positions were used, because at these positions MEGDR interpolation effects do not deteriorate the accuracy (see also discussion below). Using the original track measurements instead was not considered appropriate, because in the MEGDR potential height shifts already are eliminated.

For Candor two tracks were used, and four tracks for the wider Nanedi test site. The tracks together with a graphical representation of the results are presented in Fig. 2. In addition we have generated shaded relief representations and colour-coded difference maps of the test areas for all submitted DTMs. Sample results of the colour-coded differences are shown in Fig. 3.

In general the Candor images were more difficult to process because Candor includes very steep slopes as well as rather featureless horizontal plateaus. In addition the image quality is not as good as in the Nanedi images. Therefore, the resulting differences are larger. When
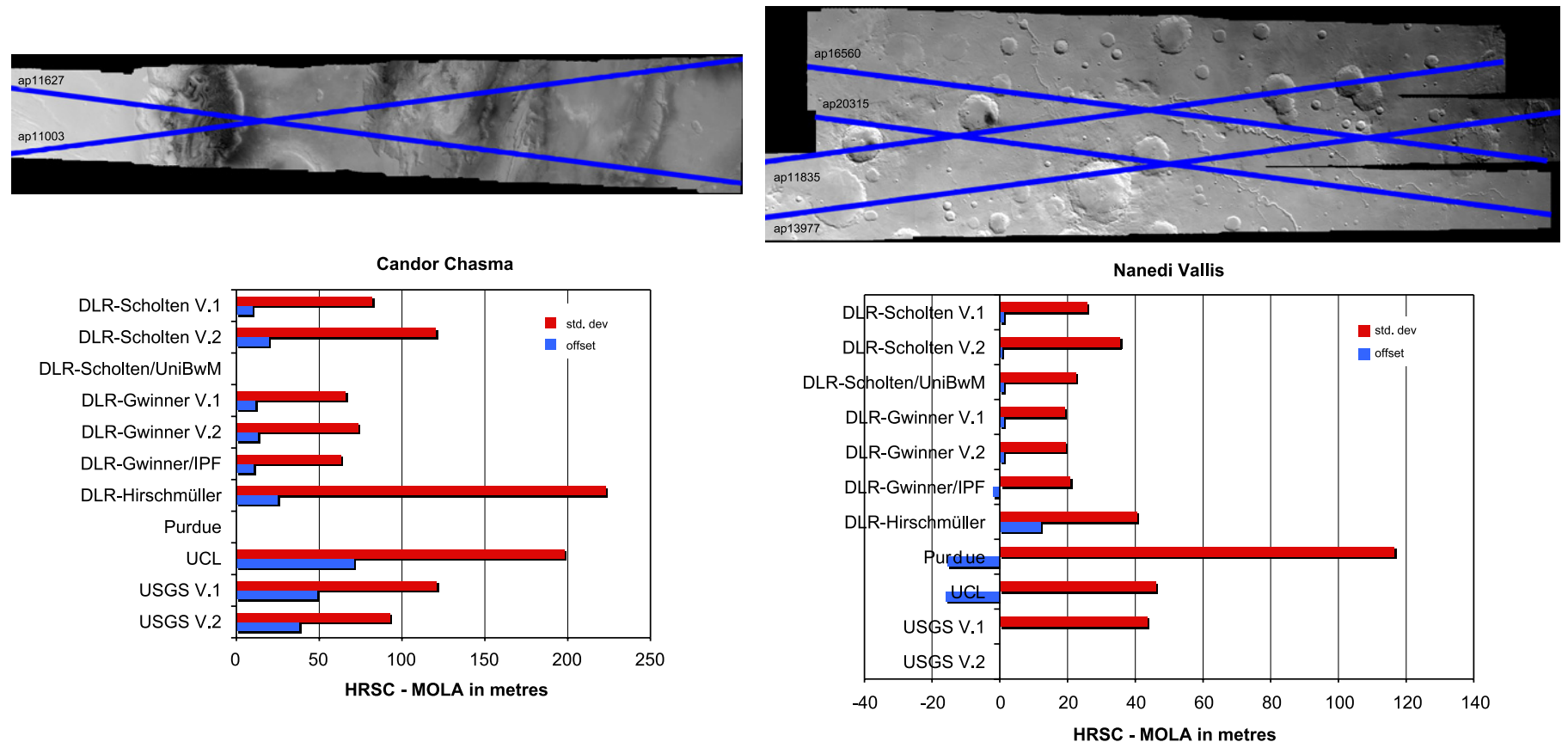

Fig. 2. Tracks (upper part) and graphical representation of statistical comparison between HRSC DTMs and the MOLA MEGDR (lower part). The given values refer to average values along MOLA tracks 11003 and 11627 (Candor) and 11835, 13977, 16560 and 20315 (Nanedi). 

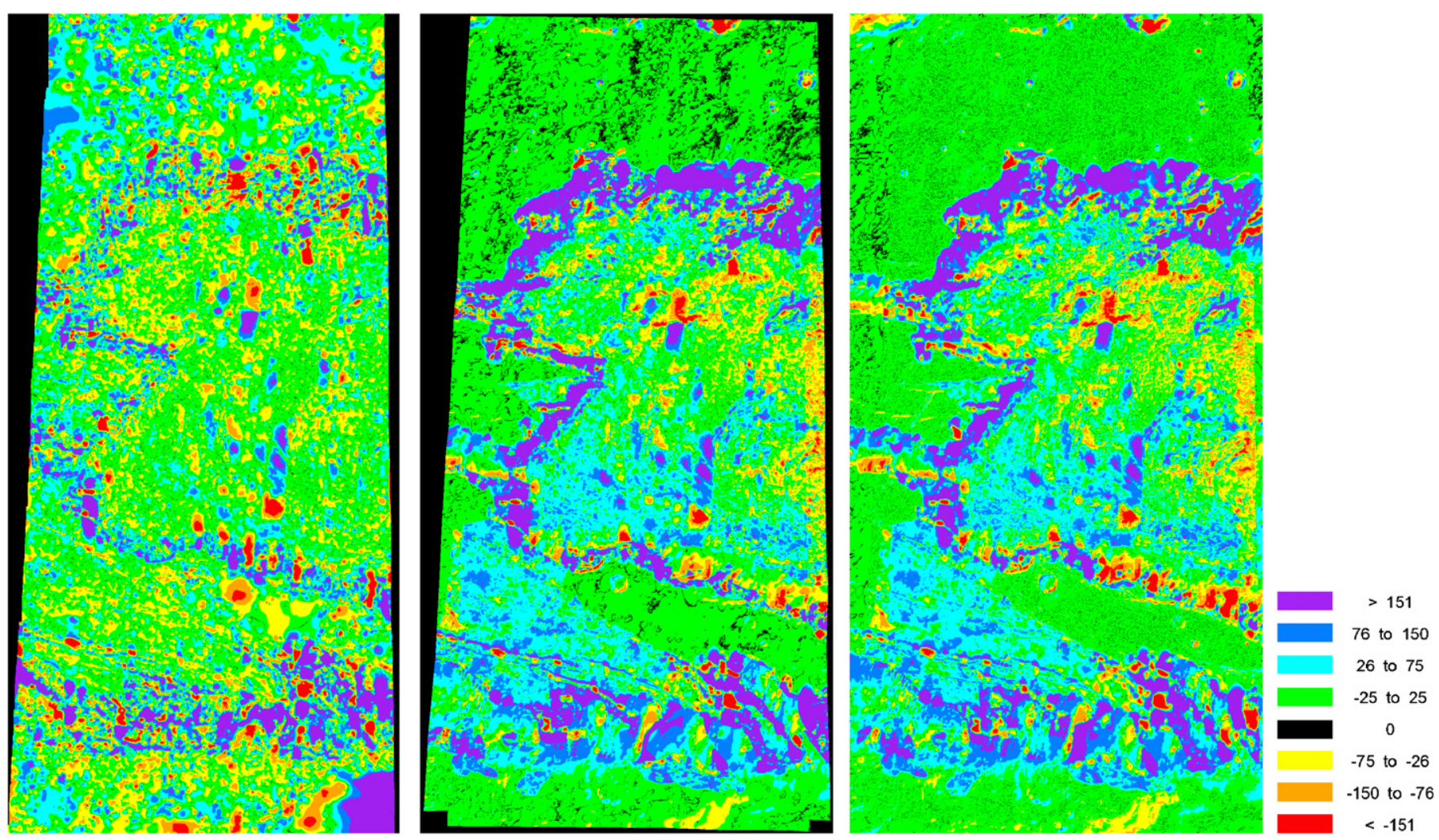

Fig. 3. Sample results of colour-coded differences between the HRSC DTM and the MOLA MEGDR, sub-area Candor Chasma. From left to right: DLR-Gwinner V.1, USGS V.1, USGS V.2. It can be seen that except for a small area in the lower right the differences are smaller for DLR-Gwinner (see also Fig. 2), and that larger differences in the USGS results primarily occur at the steep slopes. The extended green areas in the USGS results stem from the substitution of the matching results by MOLA information. Note that extrema visible in the same location and with the same spatial distribution in all three images are probably MOLA interpolation artefacts rather than errors in the HRSC DTMs. At this scale the two USGS versions show only very few noticeable differences, as is expected given that the explicit intent of the shape-from-shading refinement of USGS V.2 was to improve local details at scales of less than a few kilometres without disturbing long-wavelength components of topography; see Fig. 9 for examples of the improvement in fine detail.

analysing the results in more detail the following points became apparent:

- Most offsets are rather small. All participants employed the exterior orientation parameters by bundle adjustment using MOLA data as control information. In addition, DLR-Scholten, DLR-Scholten/UniBwM, DLR-Gwinner and DLR-Gwinner/IPF adjusted the individual 3D strips to the MEGDR. This explains the relatively small offsets. Some contributions show larger values for a few Candor results. They are probably due to a systematic bias of the results on the steep canyon walls which could be detected by inspecting the scenes in stereo (USGS, see also Fig. 3) or matching errors which were not eliminated owing to the lack of any a posteriori blunder detection (UCL).

- Offsets and standard deviations contain errors of both, the HRSC and the MOLA DTM. A detailed visual comparison of the MOLA tracks and the HRSC images revealed that despite the relatively large MOLA footprint the tracks have a very good height accuracy. As a consequence the standard deviation can be interpreted as an error measure of the HRSC DTM (note that this is not true for the complete MEGDR, see also Fig. 4 below). In flat areas, and in particular in Nanedi, some participants reached a standard deviation similar to the ground resolution of the nadir image. In areas with steep slopes the accuracy dropped to various pixels. For one matching result (contributions DLR-Gwinner and DLRGwinner/IPF for Nanedi), the standard deviation along the complete MOLA tracks shows values smaller than the ground resolution interval of the nadir image.

- The standard deviations among the participants vary considerably. However, it has to be noticed, that the groups with the lowest standard deviations used the MOLA DTM for pre-rectification and also fitted the individual DTM strips to the MOLA DTM (see Table 3), and that one participant (USGS) used MOLA for filling holes caused by blunder detection in approximately $30 \%$ of the area. While this was valid for creating the best possible results, it does somewhat reduce the significance of the numerical values. The best results were obtained by DLR-Gwinner and DLRGwinner/IPF. From these values it is not clear, however, whether the employed blunder removal technique (IPF) actually improves the results. 

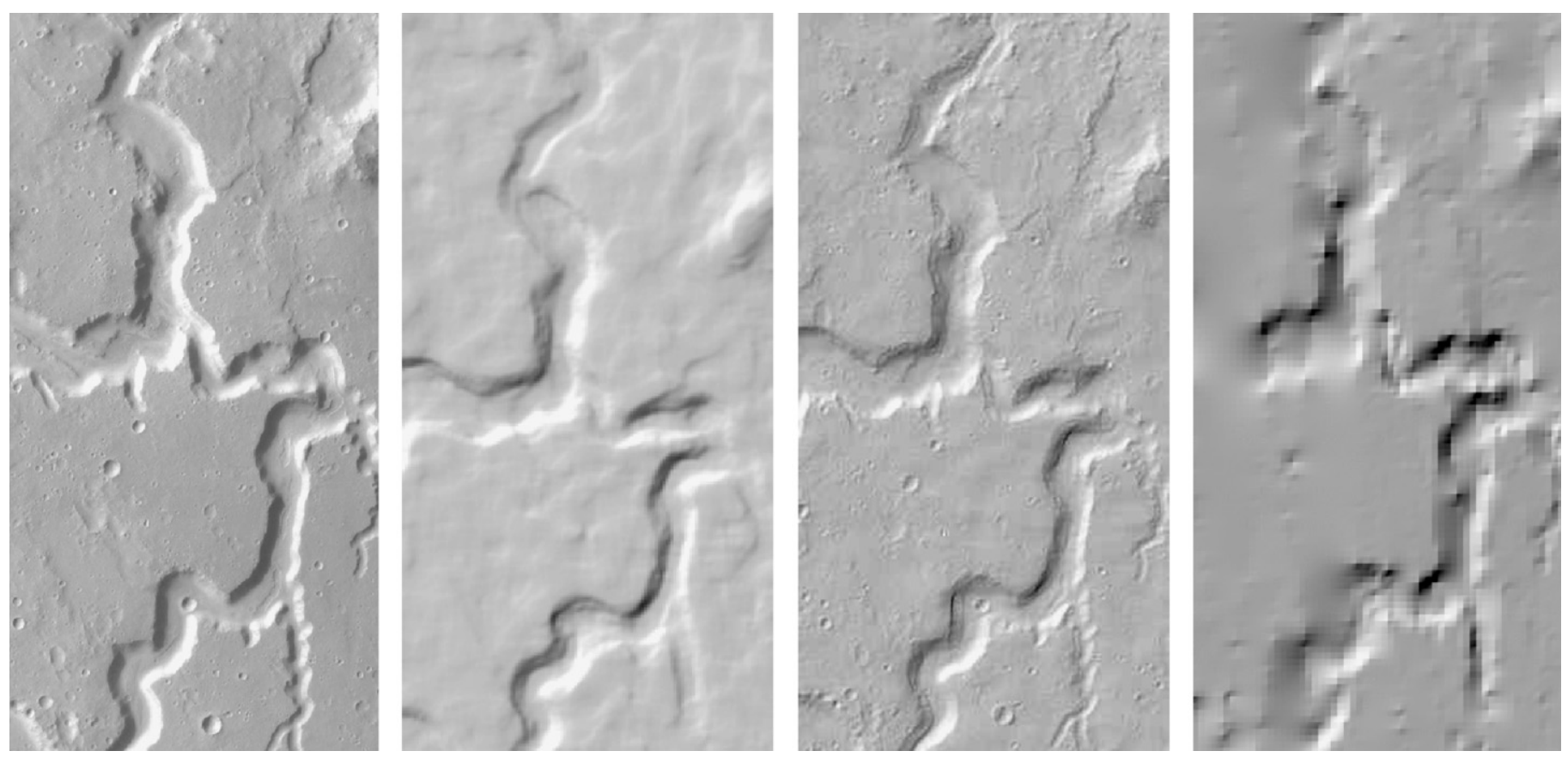

Fig. 4. Detail of the Nanedi test area, from left to right: HRSC nadir image, a matching result (DLR-Scholten V.1), a shape-from-shading result (DLRScholten/UniBwM), MOLA MEGDR (the latter three in shaded relief representation). The higher resolution of the matching DTM and in particular the shape-from-shading DTM is clearly visible. It correlates much better with the image than MEGDR.

- The participants who used more than three channels (i.e., photometry as well as nadir and stereo channels) have reached better results.

- A comparison between the two versions of DLRScholten indicates that radiometric noise reduction (in this case box filtering of the images) and additional box filtering during DTM interpolation has improved the results. This finding is supported by the fact that the shaded relief representations from V.2 look significantly noisier than those of V.1. Comparing the DLR-Gwinner results (space variant filtering and no box filtering) with those from DLR-Scholten further supports the importance of radiometric pre-processing. Note, however, that previous work (Gwinner et al., 2005) shows that noise reduction by box filtering with fixedsize filter windows, in contrast to the space variant technique, often fails to improve point accuracy and density.

- The SFS techniques do improve the results. The quantitative comparison (Figs. 2 and 3) indicates, however, that the improvements are related mainly to the local scale (see also Figs. 8 and 9), while overall (larger scale) differences to MOLA heights tend to persist.

- Commercial software (USGS), software developed for other types of images (DLR-Hirschmüller developed for terrestrial urban HRSC scenes with many height discontinuities) and prototype software (Purdue) yield somewhat less accurate results than approaches specifically developed for planetary images, in particular when dealing with difficult scenes (Candor).
- It was not possible to adequately process images with varying integration time using SOCET SET (USGS, Nanedi). The colour-coded difference map clearly shows long wavelength effects stemming from problems in enforcing consistency between the image segments of constant integration time in the exterior orientation.

- In the shaded relief representation of DLR-Hirschmüller a number of tile borders are visible, in particular for Nanedi.

- While being of a very high nominal resolution the UCL DTMs suffer from a lack of blunder reduction.

Experiments were also conducted with the software, which DLR employs to generate preliminary DTMs using the nominal exterior orientation values as input. These experiments resulted in an offset of up to $100 \mathrm{~m}$ in height, this offset being significantly different for the different Nanedi images. Thus, a refinement of the nominal exterior orientation values by bundle adjustment is necessary to consistently tie together different images in a block and to make the results compatible with MOLA (see also Schmidt et al., 2005; Spiegel et al., 2005).

A two-dimensional comparison of a part of the Nanedi test site was carried out in a second step. The results clearly show that the MOLA MEGDR can only be considered as a geometric reference along the MOLA tracks, because in two dimensions the reduced ground resolution of the MEGDR becomes clearly apparent (see Fig. 4). Differences between the HRSC DTM and the MEGDR were predominantly found along slopes and undulating terrain. They thus tend to represent the lower resolution of the 
MEGDR rather than matching errors in the HRSC results. This finding is exemplified in Fig. 4, which shows from left to right a part of the Nanedi nadir image and shaded relief representations of the DLR-Scholten V.1 result, the DLRScholten/UniBwM result and the MEGDR. Since both test areas (Candor and Nanedi) are located near the equator, these findings confirm previous reports on improved detail of HRSC DTMs with respect to MEGDR at lower latitudes (Scholten et al., 2005b; Gwinner et al., 2005).
Similar representations are contained in Fig. 5, which shows a detail of the Nanedi test site with many craters depicted by thin red circles. Shaded relief representations give a good impression of the quality of delivered DTMs, especially when compared to the HRSC nadir image (lower right). Lower levels of detail can be observed readily for the lowest resolution DTMs when compared to some of the higher resolution DTMs (see Table 4). However, the degree with which additional resolved detail is provided by the

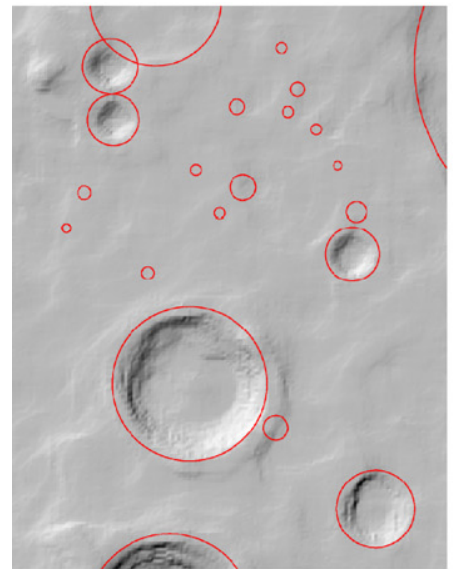

DLR-Scholten V.1

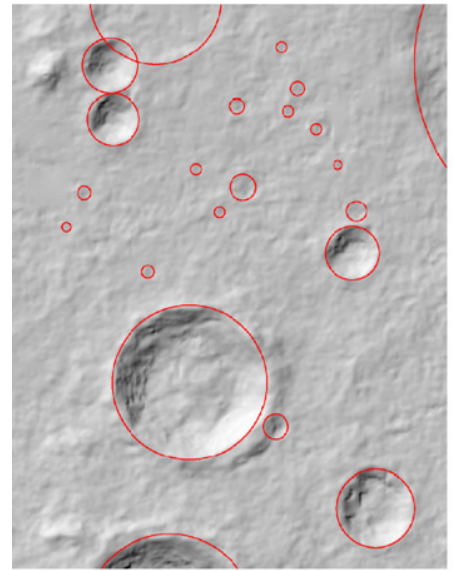

DLR-Gwinner/IPF

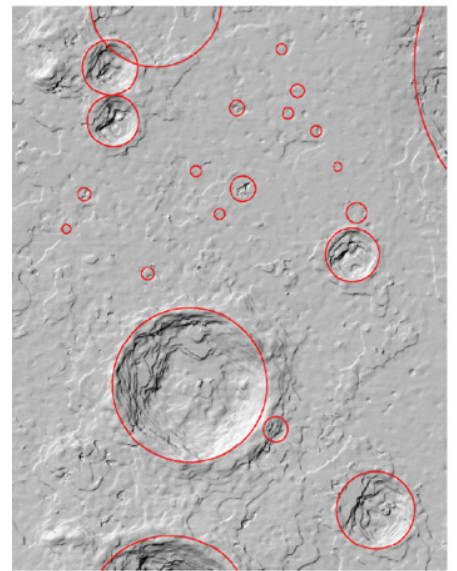

UCL

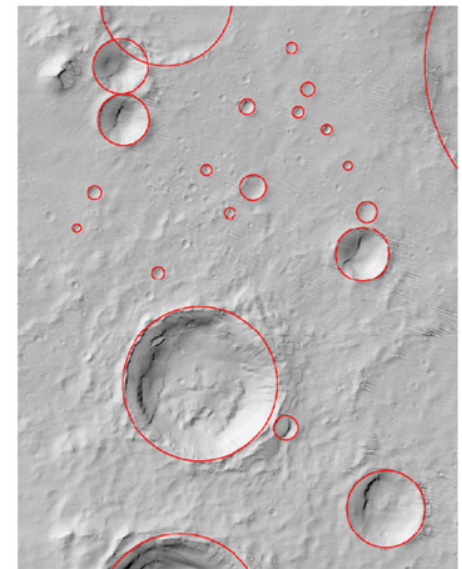

DLR-Scholten / UniBwM

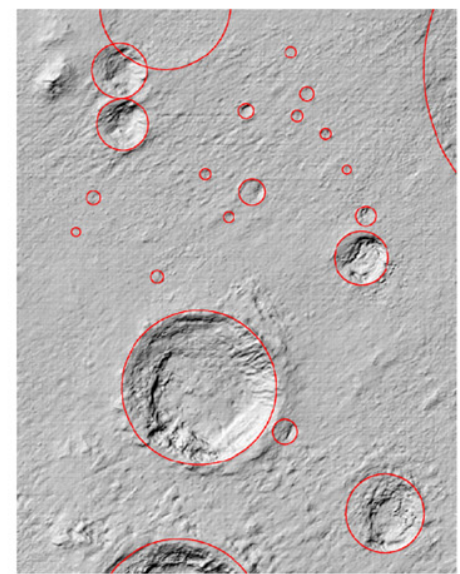

DLR-Hirschmüller

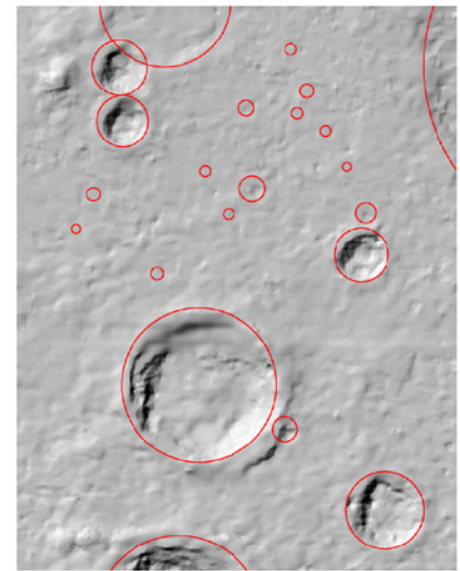

USGS

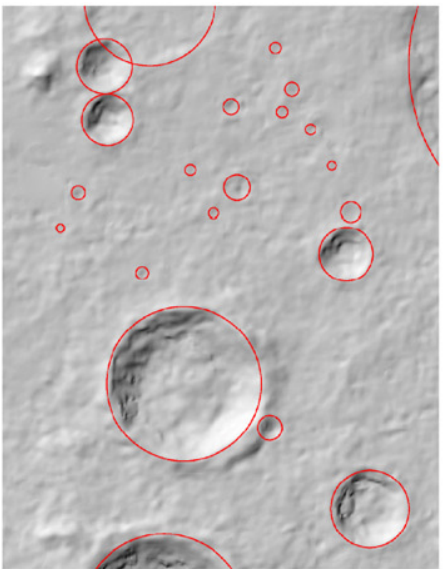

DLR-Gwinner V.1

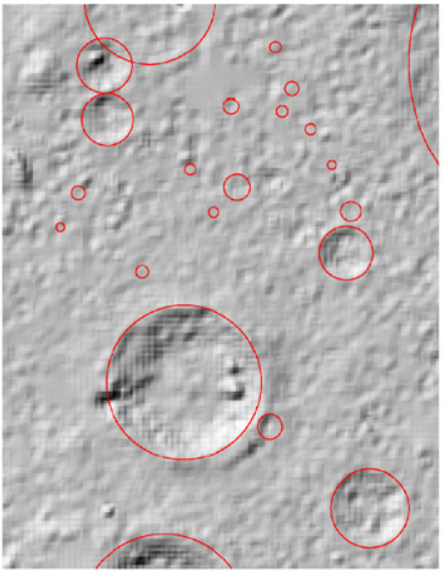

Purdue

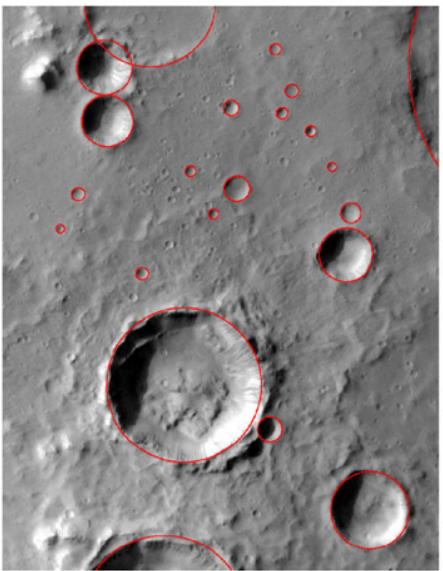

HRSC nadir image

Fig. 5. Detail of the Nanedi test site, shaded relief representations of the different DTMs in comparison to HRSC nadir image (lower right). 
contributions with the smallest grid spacing is less obvious. While some approaches are able to generate very consistent results with the impression from the grey value image, others contain considerable noise or artefacts. In general the findings from Fig. 2 are supported when examining Fig. 5 in more detail. The DTM resolution appropriate for the individual results is further discussed in Section 5.3 below.

\subsection{Superposition of DTMs and height contours}

In the next evaluation step height contours were generated from the delivered DTMs. Height contours should represent the general morphology of the terrain. In particular in planetary images with rather constant albedo a comparison with the images gives a very clear indication of the DTM quality. The contours were computed using the approach described in Gehrke et al. (2005) and were superimposed on HRSC orthophotos provided by DLRScholten. ${ }^{4}$ The contour interval was $250 \mathrm{~m}$ for Candor and $100 \mathrm{~m}$ for Nanedi. Sample results for areas of $11 \times 17 \mathrm{~km}^{2}$ are contained in Figs. 6-8. From these figures differences between the DTMs can be observed, which in many cases correspond rather well to the quantitative results. In Fig. 6, for example, the valley is well represented in the height contours of the DLR-Scholten, DLR-Scholten/UniBwM, DLR-Gwinner, DLR-Gwinner/IPF and USGS results, whereas the other contours represent the terrain somewhat less well. In agreement with its $200 \mathrm{~m}$ resolution, the contours from DLR-Scholten tend to be less representative at small scale features such as the tributary valleys in the Eastern half of the image. The DLR-Hirschmüller approach seems to generate a nearly vertical wall in the darker part of the valley. In some parts of the contours from Purdue noise and artefacts from the matching result can be found. Note also that some of the smaller craters, which can be seen very well in the images, appear not to be resolved in most DTMs. This is for instance the case for the crater in the centre of Fig. 7. Even the SFS technique DLRScholten/UniBwM is not able to resolve this crater; however, other fine detail is represented very well. Overall, the general trends observed in the other evaluation steps are reinforced by the study of the height contour results.

In Fig. 8 the refinement possible by SFS can be clearly made out once more, compare for instance the set of contours in the upper part of the scene. A more detailed view of the potential of SFS is presented in Fig. 9 which shows a significant improvement in terms of visible detail although the absolute heights are not improved with respect to the matching results (see also Figs. 2 and 3). In summary, very detailed DTMs can be generated from the

\footnotetext{
${ }^{4}$ Strictly speaking each set of contours should have been superimposed on the corresponding orthophoto. However, we had only the DLRScholten orthophoto available to us. As a result slight lateral displacements between the contours and the orthophoto may appear, and these should not be interpreted as DTM errors.
}

HRSC images. As is visible from Fig. 9 at least in some areas it is feasible to use a DTM grid size of three times the resolution of the nadir image. On the other hand it should also be noted that in classical SFS certain assumptions such as spatially constant albedo and Lambertian or LommelSeeliger reflection are introduced, and atmospheric effects are ignored. The approaches investigated in this paper address these shortcomings by sophisticated interactive and automatic pre-processing (DLR-Scholten/UniBwM and USGS) and by employing more realistic photometric functions (USGS). Nevertheless, the assumptions and the resulting effects somewhat limit the applicability of SFS to larger areas.

\subsection{DTM resolution}

The grid spacing of the different DTMs was selected by the participants according to their judgement (see also Table 4). This raises the question of whether the various datasets contain geologically real and useful details down to the limit imposed by the chosen grid spacing, in which case an even finer grid might have recorded additional details, are appropriately sampled, or perhaps are substantially smoother than the grid spacing alone might indicate. The answer can be quantified, to some extent, by slope-baseline analysis of the various DTMs. We use the approach of Kirk et al. (2003) to calculate the bidirectional root mean square (RMS) slope over all possible distances (baselines) separating pairs of DTM points in a given direction from the one-dimensional autocovariance function of the topography, which may be calculated efficiently by fast Fourier transform methods. Kirk et al. (2003) showed that results calculated in this way agree with explicit calculation of RMS slopes, provided that care is exercised in avoiding end effects. They also verified that disparate datasets (e.g., MOLA altimetry, stereo and SFS from images of various resolutions, and in situ measurements by landers) give consistent results even when the regions analysed are overlapping but not identical. The RMS slope is equivalent to another common statistical measure of topographic details, the Allen deviation (Shepard et al., 2001), divided by the baseline, and logarithmic plots of either function show equivalent information. End effects generally invalidate the results at baselines greater than 0.1 to at most 0.5 of the width of the region analysed, causing a downturn of the curve at the largest baselines. A consistent linear trend on such a plot is indicative of self-affine (fractal) scaling, and is often observed over at least a moderate range of intermediate baselines; a break in the curve may indicate a change in the dominant geomorphic feature with scale. The trend may continue to the shortest baselines, but if the surface is locally smoothed (e.g., by some process such as dust mantling) or the DTM is artificially smoothed, the curve will roll over to a constant RMS slope value. Conversely, artefacts at the scale of the grid spacing may cause the slope-baseline curve to turn upward at short baselines, but 


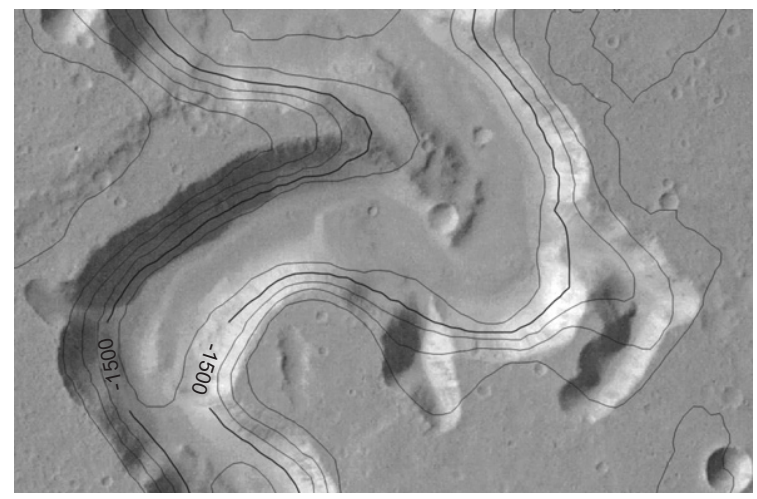

DLR-Scholten, V.1

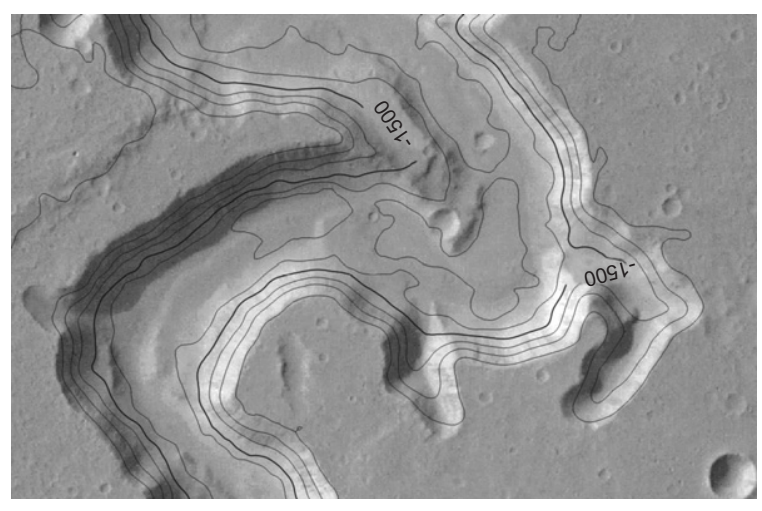

DLR-Gwinner V.1

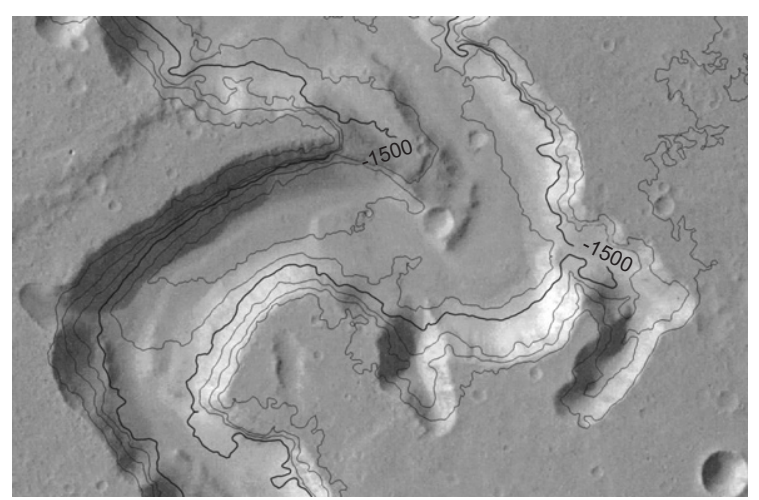

DLR-Hirschmüller

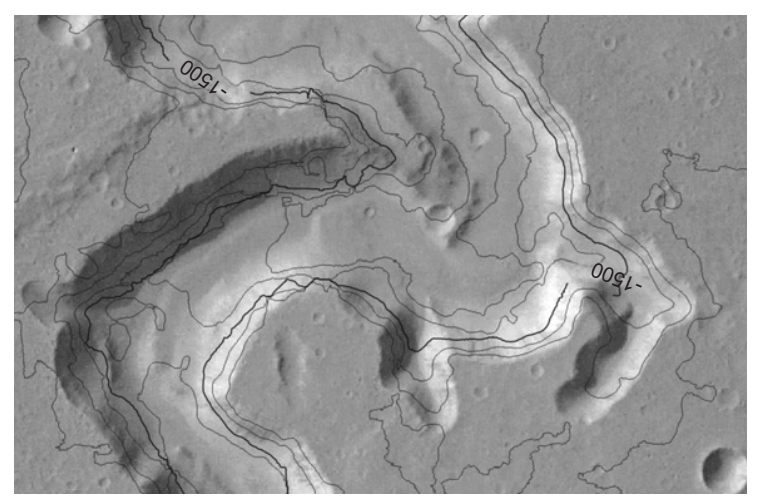

UCL

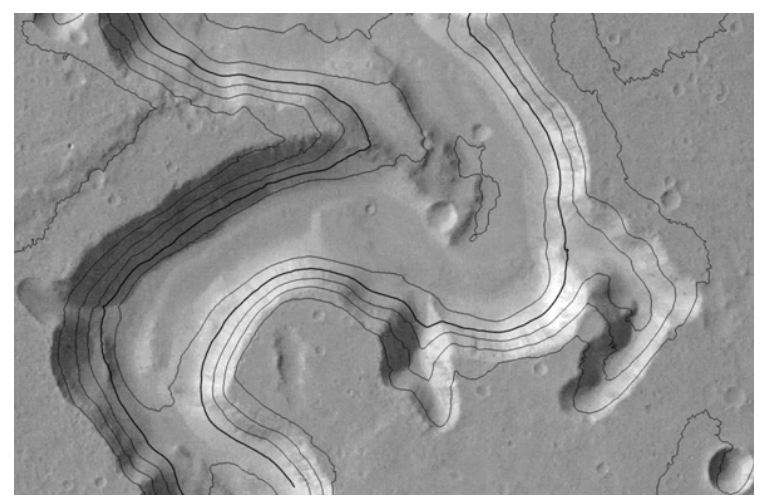

DLR-Scholten/UniBwM

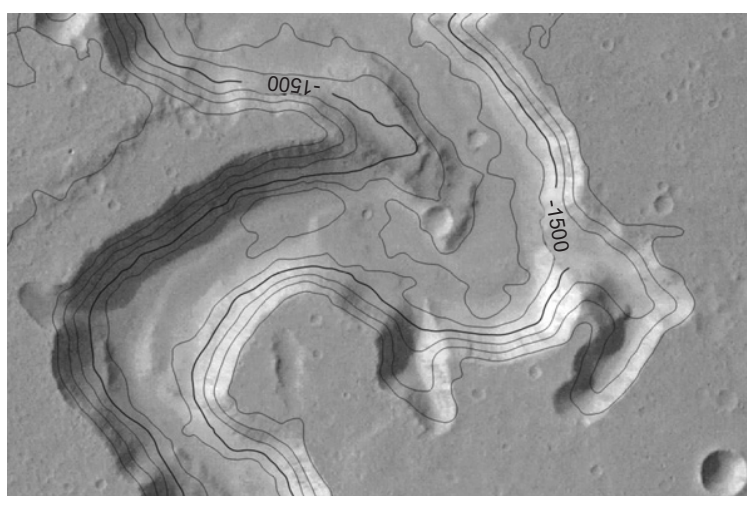

DLR-Gwinner / IPF

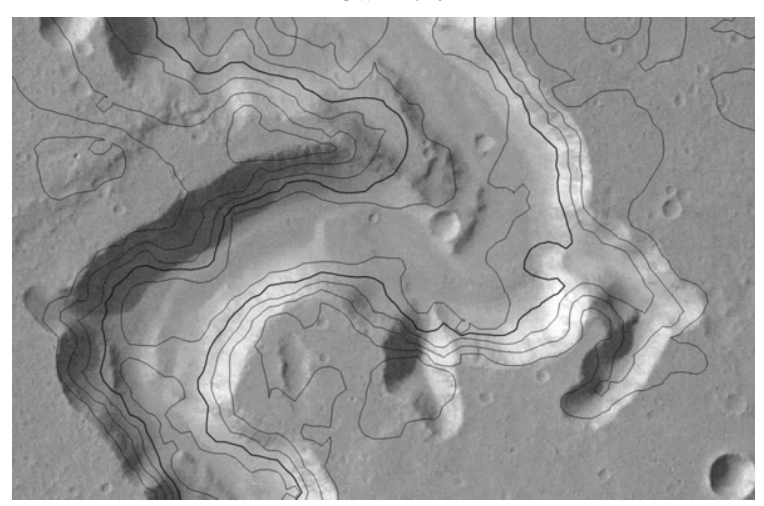

Purdue

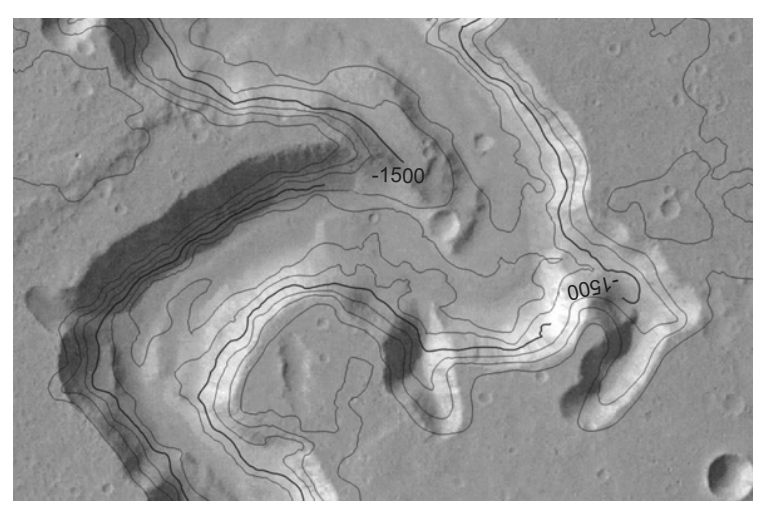

USGS V.1

Fig. 6. Part of Nanedi test area $\left(11 \times 17 \mathrm{~km}^{2}\right)$, HRSC orthophoto with superimposed height contours, contour interval $100 \mathrm{~m}$. 


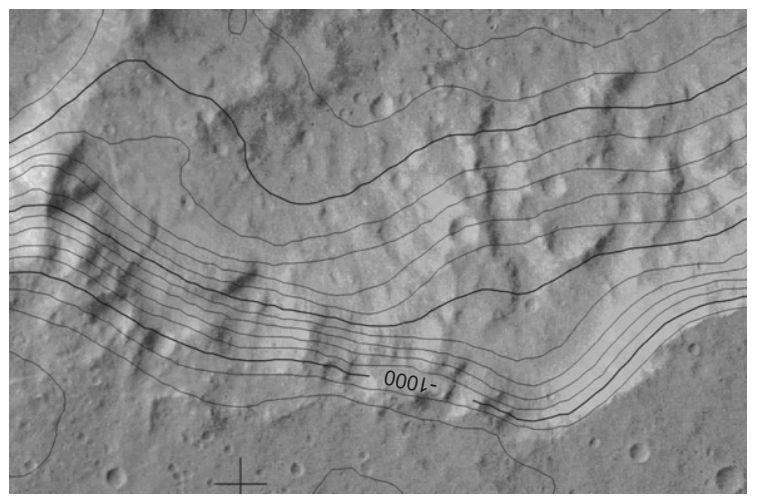

DLR-Scholten, V.1

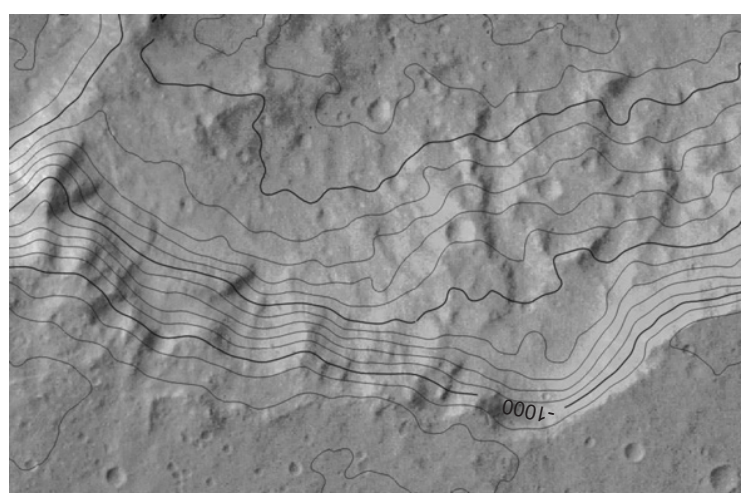

DLR-Gwinner, V.1

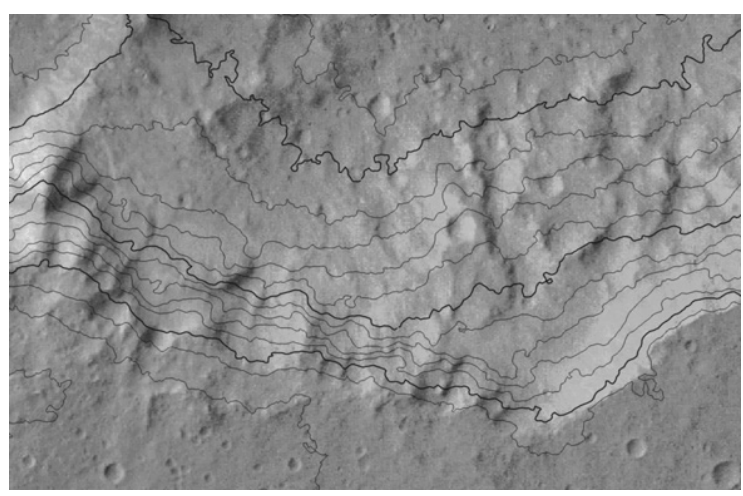

DLR-Hirschmüller

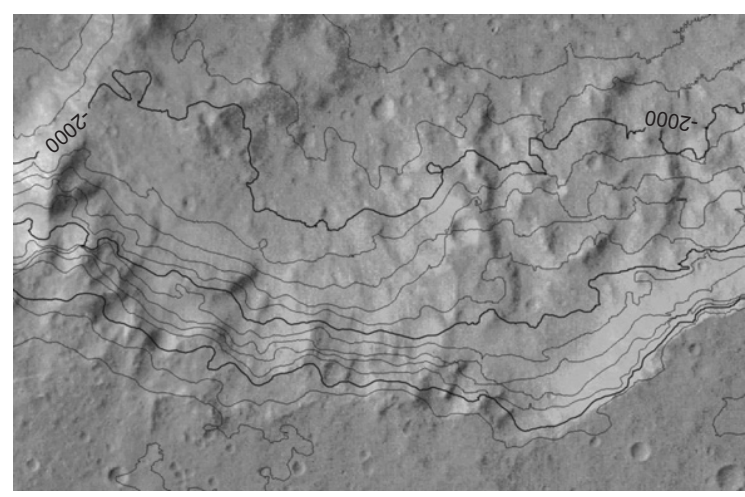

UCL

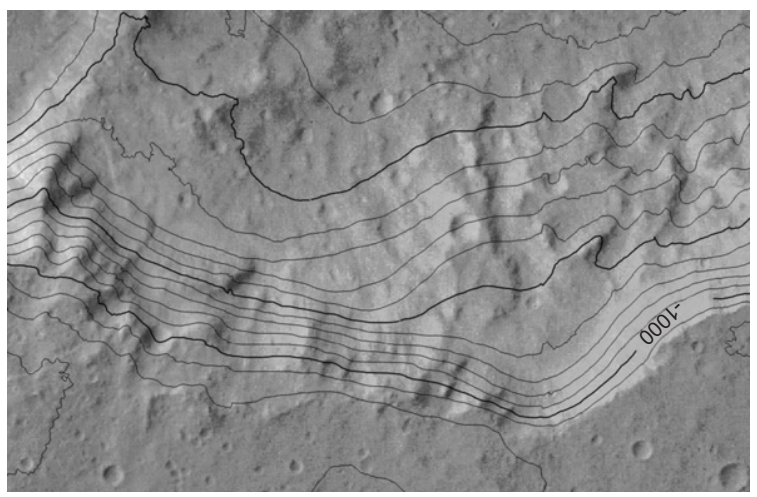

DLR-Scholten / UniBwM

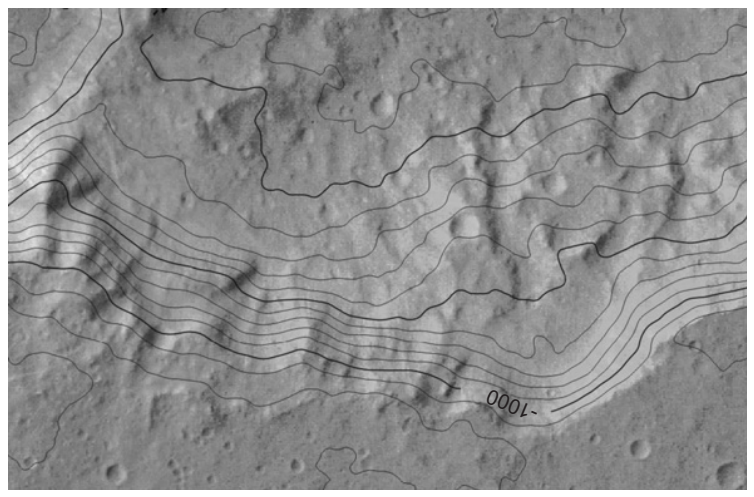

DLR-Gwinner / IPF

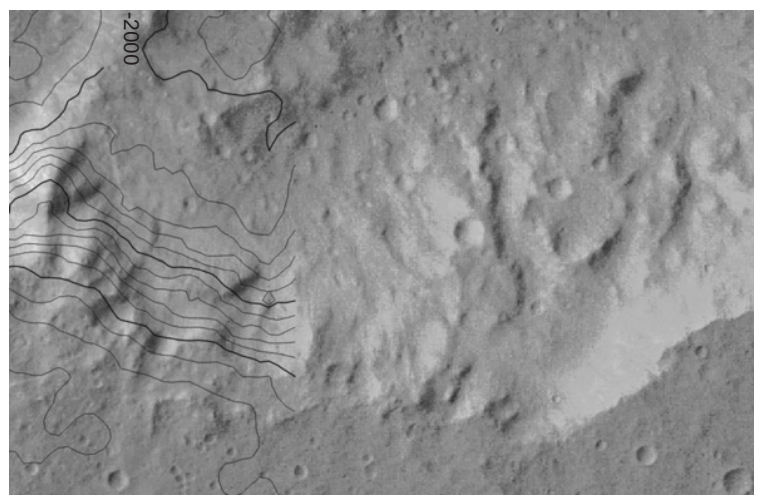

Purdue (no DTM data in right part of image)

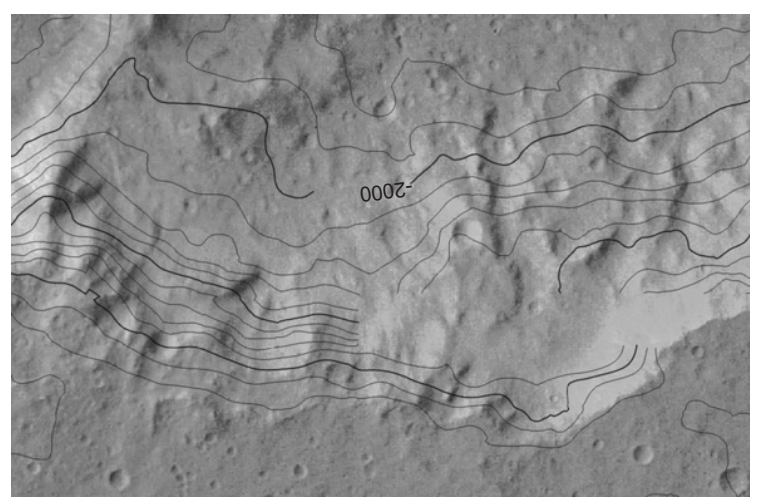

USGS V.1 (data gap in the lower right part)

Fig. 7. Part of Nanedi test area $\left(11 \times 17 \mathrm{~km}^{2}\right)$, HRSC orthophoto with superimposed height contours, contour interval $100 \mathrm{~m}$. 


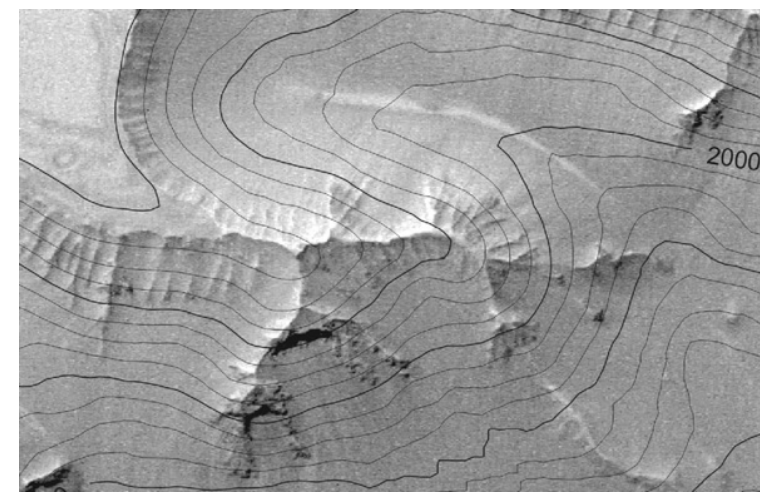

DLR-Scholten, V.1

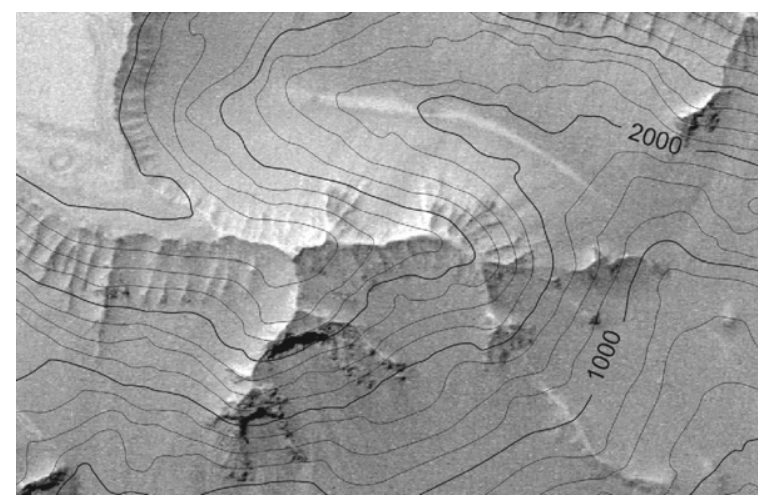

DLR-Gwinner / IPF

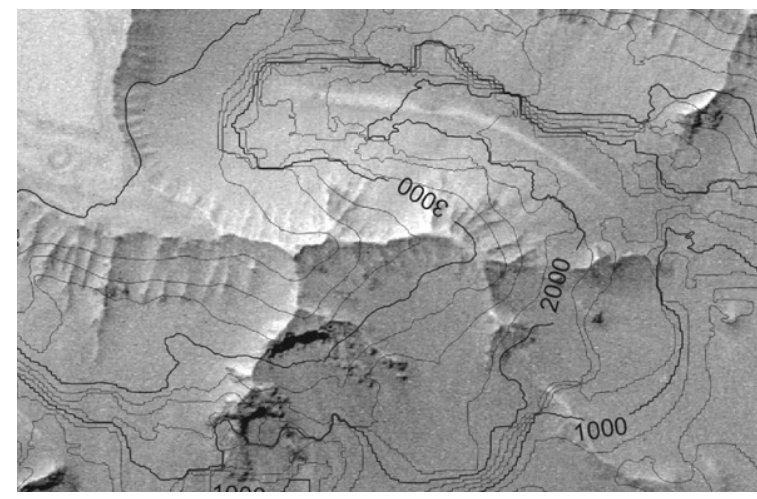

UCL

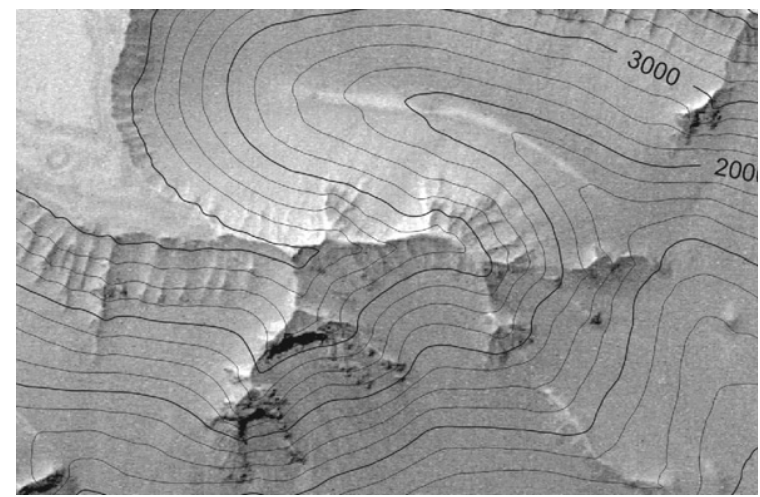

USGS V.2

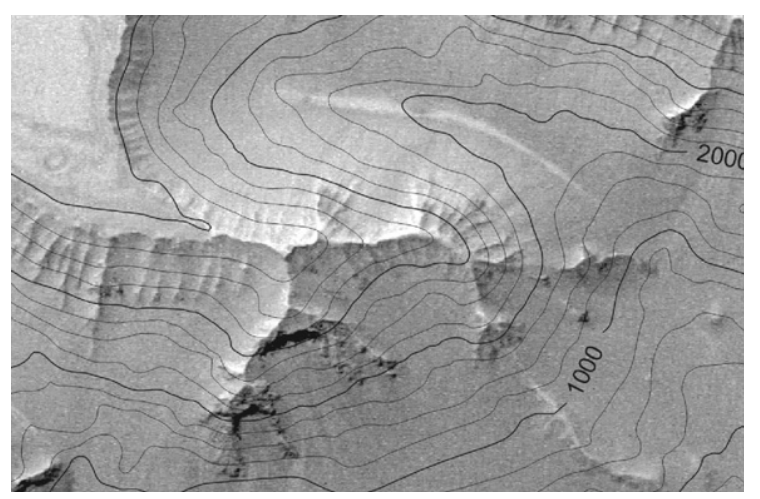

DLR-Gwinner, V.1

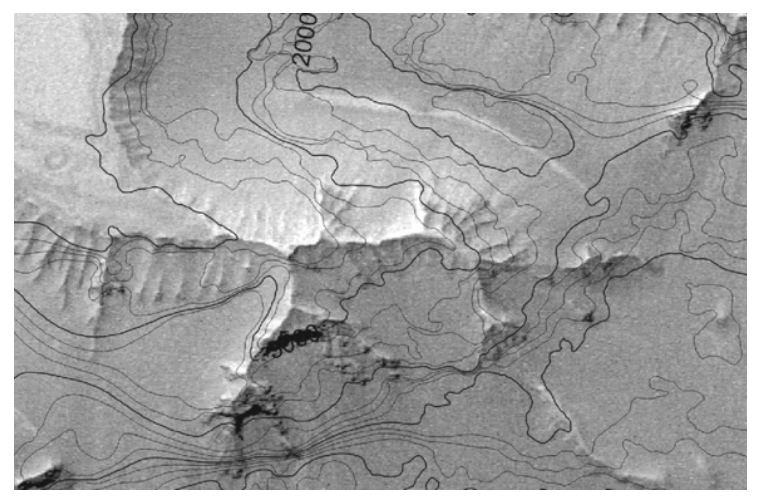

DLR-Hirschmüller

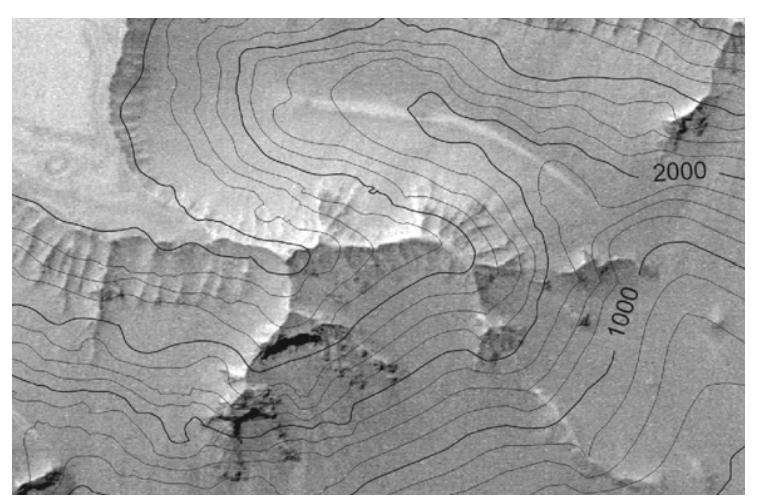

USGS V.1

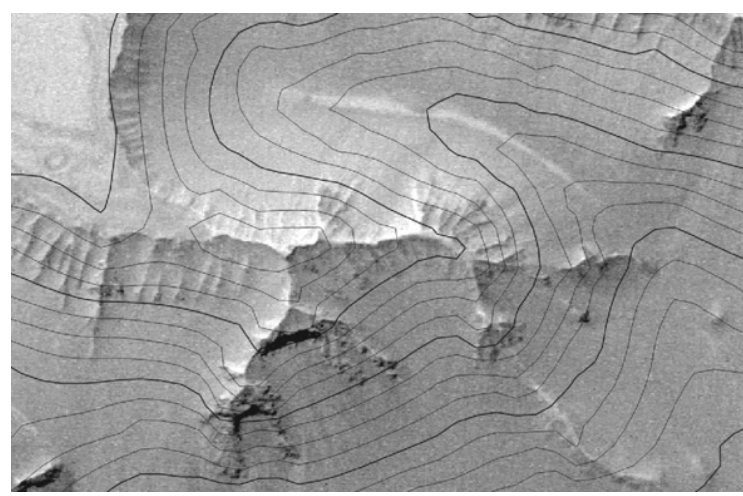

MOLA MEGDR

Fig. 8. Part of Candor test area $\left(11 \times 17 \mathrm{~km}^{2}\right)$, HRSC orthophoto with superimposed height contours, contour interval $250 \mathrm{~m}$. 

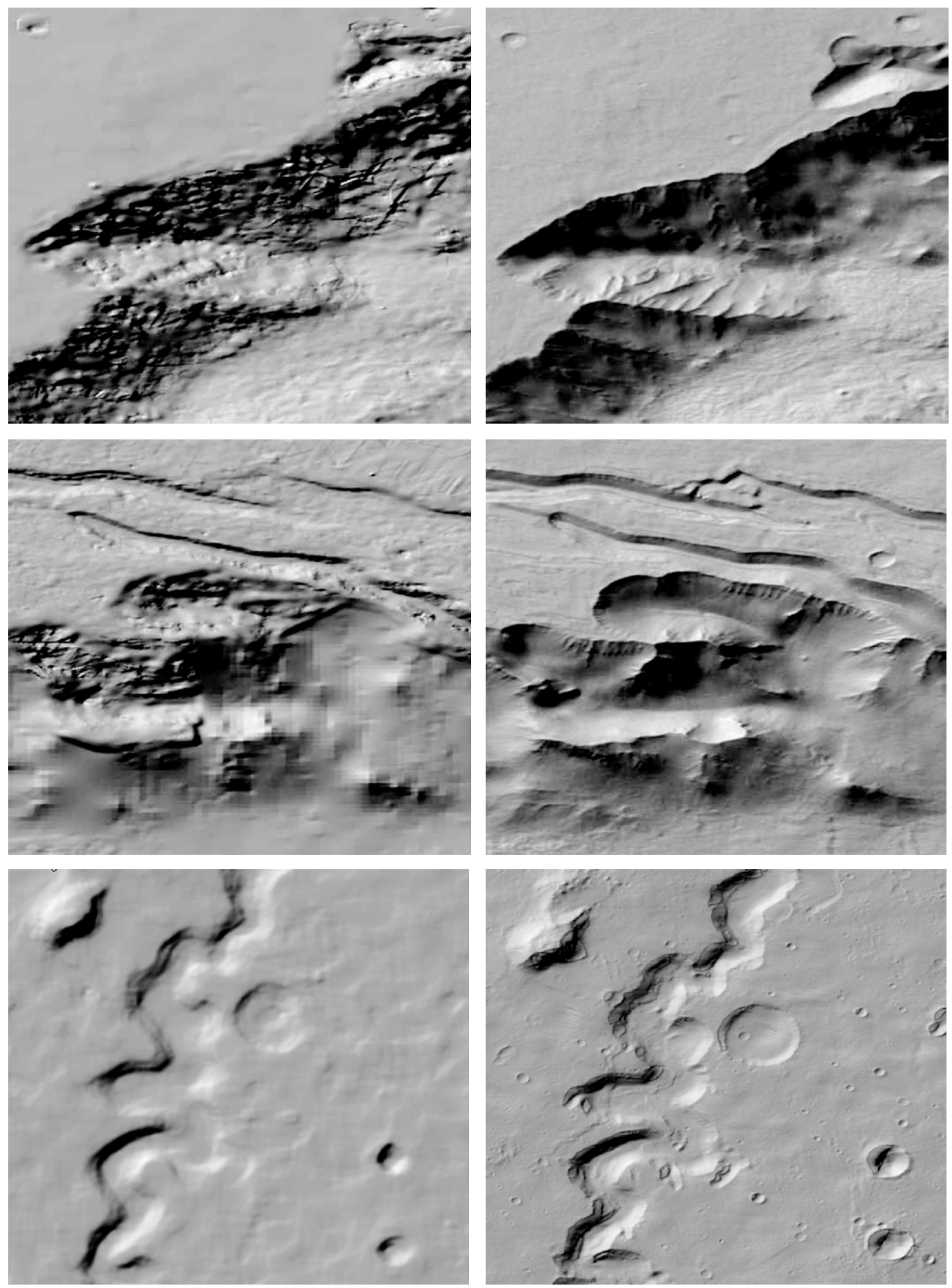

Fig. 9. Comparison between the matching and shape-from-shading results for three small areas. Upper and centre: Candor Chasma in shaded relief representation: before (left) and after (right) refinement by shape-from-shading (USGS solution). Lower: similar representation for detail from Nanedi scene (DLR-Scholten/UniBwM solution).

so may real geologic features of similar scale. Thus, though the slope-baseline curves provide useful information about the scale of features captured by a given DTM, they must be interpreted with care in light of the appearance of the DTM, in particular, whether the finest details are geologically real or a spurious result of the mapping process.
Fig. 10 shows slope-baseline curves for the DTMs in this study, for slopes in the east/west direction for part of the Nanedi sub-area. The analysed area was chosen to be as similar as possible, given the different grid spacings used and the need to select a region $2^{n}$ samples wide for Fourier analysis. The slight differences in the area analysed primarily affect the slope estimates at the longest baselines. 


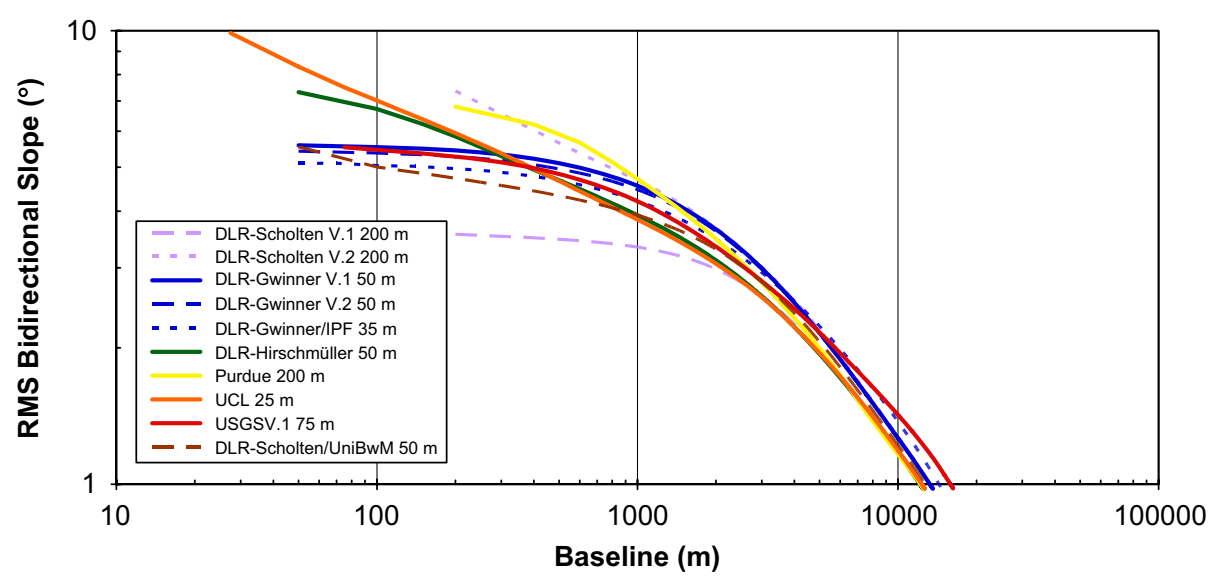

Fig. 10. Plot of the RMS bidirectional slope versus baseline.

Apart from this effect, the slopes at long to intermediate baselines (down to approximately $3000 \mathrm{~m}$ ) are similar for all DTMs. Differences between the datasets become increasingly apparent at shorter baselines, however.

The DLR-Scholten/UniBwM provides a useful basis for comparison with the other models at small baselines. Inspection of contours (Fig. 8) and particularly shaded relief portrayals (Fig. 9) indicates that the SFS refinement contains real geomorphologic detail. Along those lines we can conclude that the DLR-Scholten V.1 DTM contains substantially lesser fine detail (smaller short baseline slopes) and is significantly smoothed compared to the real surface. Note that the DLR-Scholten/UniBwM curve has a small upturn at baselines smaller than $200 \mathrm{~m}$. This suggests that while SFS was successful at small baselines (relative heights and thus local detail), the medium size and the more global aspects for this solution are less well captured, the RMS slope of the DLR-Gwinner and the USGS V.1 solutions seem to provide more real information at baselines larger than $200 \mathrm{~m}$. With respect to these results the DTMs of DLR-Hirschmüller, UCL, Purdue and DLRScholten V.2 seem to be dominated by artefacts at smaller baselines (see also Figs. 5-7 and 9). Finally, it should be noted that while this study is useful in studying and comparing the different DTM solutions, the resulting plot is not intended to serve for determining the appropriate DTM resolution directly. In order to do so, visual inspection of the results is seen as indispensable.

\subsection{Crater detection}

As another step to investigate the quality of the derived DTMs we have manually extracted crater features from the DTMs of the Nanedi block. Note that we do not suggest to actually do crater detection based on the DTMs. Rather, we used the number of detected craters as a relative measure of detail to compare the different DTMs. We first delineated all visible craters in the HRSC orthophoto mosaic and classified them according to their diameter with a class width of $1 \mathrm{~km}$. These craters were then super- imposed onto shaded relief representations of each derived DTM, and for each class the number of craters which could be recognised in the DTM was recorded. The crater depth was not taken into account. Altogether, about 2800 craters were investigated in each DTM covering the whole orbits; less craters were investigated for participants who had only processed the sub-areas. After visual checking we combine the results under the assumption that the sub-areas are representative for the whole orbits in terms of crater density and preservation. The results of the investigation are depicted in Fig. 11. As can be seen, a crater must measure a number of pixels in width in order to be detected (see again Table 4 for the DTM resolution). Small craters are best detected in the SFS results of DLR-Scholten/ UniBwM, which is another piece of evidence that SFS adds real detail to the matching results. Among the latter the DLR-Gwinner and DLR-Gwinner/IPF results contain the most detail, while we are again led to conclude that some of the other DTMs with a nominally very high resolution seem to contain artefacts at smaller scale rather than real geomorphologic information.

\subsection{Operational aspects}

Finally, the operational aspects of the different algorithms are addressed. In our view, an operational procedure is one which can be used to process large areas (multiple orbits, potentially the whole HRSC data set). Thus, besides accurate and reliable results and a high degree of automation fast generation of the results is a prime indicator of an operational solution. We have chosen to use the computational time necessary to generate the DTMs as reported by the participants as a measure (Table 5). When interpreting the timings one has to keep in mind that different processors and different coding languages were used, in many cases recoding or parallel computing can significantly accelerate the process, and semi-automatic approaches cannot easily be compared with automatic ones in terms of computing time. Also, the DTM resolution chosen by the participants often has a significant influence. 


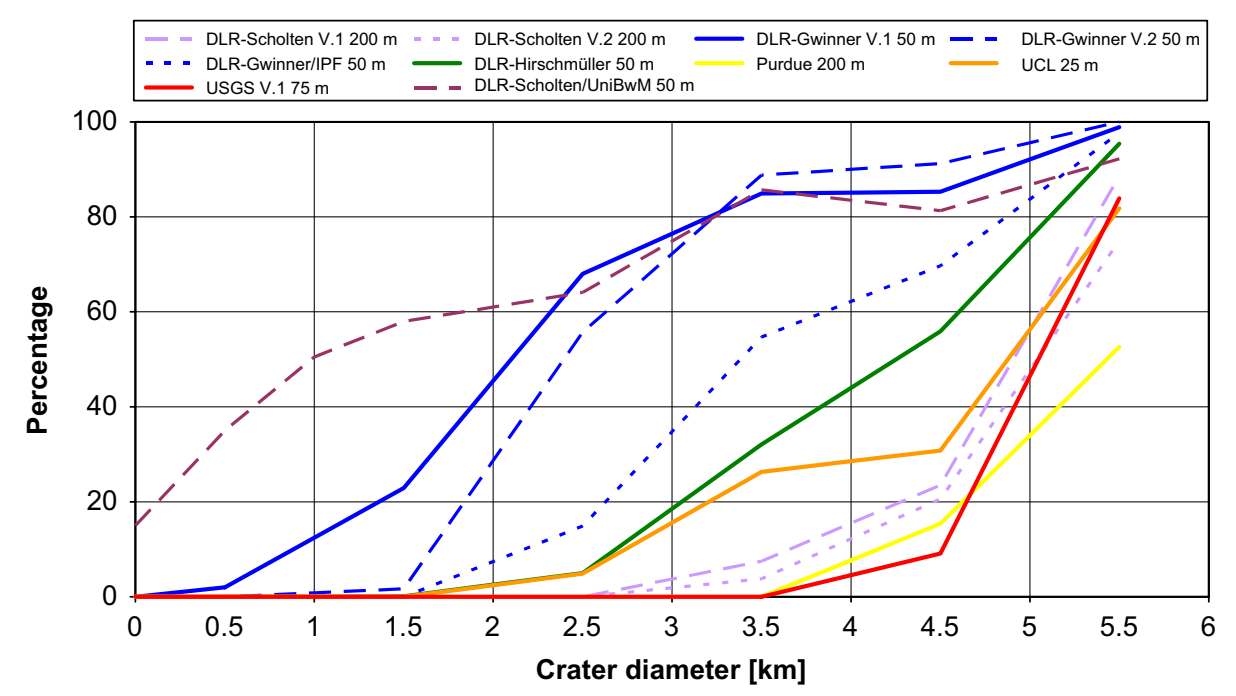

Fig. 11. Percentage of craters detectable in the derived DTMs for each participant.

Table 5

Operational aspects of different approaches and CPU time for processing both test areas

\begin{tabular}{|c|c|c|c|c|c|}
\hline \multirow[t]{2}{*}{ Test participant } & \multicolumn{3}{|l|}{ Performance } & \multirow[t]{2}{*}{ Hardware } & \multirow[t]{2}{*}{ Remarks } \\
\hline & CPU time $(\mathrm{h})$ & $\begin{array}{l}\text { area } \\
\left(10^{3} \times \mathrm{km}^{2}\right)\end{array}$ & $\begin{array}{l}\text { time }(\min / \\
\left.10^{3} \times \mathrm{km}^{2}\right)\end{array}$ & & \\
\hline DLR-Scholten & 4 & 500 & 0.48 & $2.8 \mathrm{GHz}$ Xeon & $\begin{array}{l}\text { Whole orbits } \\
\text { noise reduction (V.2) negligible }\end{array}$ \\
\hline $\begin{array}{l}\text { DLR-Scholten/ } \\
\text { UniBwM }\end{array}$ & $2.8+3$ man. & 72 & 2.3 & 3.0 GHz Xeon & $\begin{array}{l}\text { Sub-area, Nanedi only } \\
\text { must be added to timing of DLR-Scholten } \\
3 \mathrm{~h} \text { man. refers to haze-gain correction }\end{array}$ \\
\hline DLR-Gwinner & 277 & 500 & 33.2 & $2.8 \mathrm{GHz}$ Xeon & $\begin{array}{l}\text { Whole orbits } \\
\text { includes CPU time for test runs to tune parameters } \\
\text { in addition } 36 \mathrm{~h} \text { manual work required }\end{array}$ \\
\hline $\begin{array}{l}\text { DLR-Gwinner/ } \\
\text { IPF }\end{array}$ & 420 & 500 & 40.8 & $\begin{array}{l}2.41 \mathrm{GHz} \text { AMD } \\
\text { Opteron } 250\end{array}$ & $\begin{array}{l}\text { Whole orbits } \\
\text { CPU time includes approximately } 80 \% \text { of time of DLR- } \\
\text { Gwinner }\end{array}$ \\
\hline $\begin{array}{l}\text { DLR- } \\
\text { Hirschmüller }\end{array}$ & 92 & 500 & 11.0 & $2 \mathrm{GHz}$ Opteron & $\begin{array}{l}\text { Whole orbits } \\
\text { time depends largely on matching resolution, can be } \\
\text { reduced to under } 9 \mathrm{~h} \text { using } 30 \mathrm{~m} / \text { pixel for all images, } \\
\text { time can be significantly reduced by parallel processing }\end{array}$ \\
\hline Purdue & 45 & 90 & 30.0 & $3.1 \mathrm{GHz}$ P4 & Whole orbit, Nanedi 905 only \\
\hline UCL & 192 & 113 & 102.0 & $2.4 \mathrm{GHz}$ Xeon & $\begin{array}{l}\text { Sub-areas } \\
\text { elapsed time, hardware shared with other users }\end{array}$ \\
\hline USGS V.1 & $\begin{array}{l}13.7+109 \\
\text { man. }\end{array}$ & 95 & 8.6 & $\begin{array}{l}1.5 \mathrm{GHz} \text { Blade } \\
1500\end{array}$ & $\begin{array}{l}\text { Sub-areas, Nanedi } 927 \text { not processed, } \\
\text { semi-automatic approach, } 109 \mathrm{~h} \text { refers to manual part }\end{array}$ \\
\hline USGS V.2 & 0.4 & 41 & 0.6 & $\begin{array}{l}500 \mathrm{MHz} \mathrm{G} 4 \\
\text { laptop }\end{array}$ & $\begin{array}{l}\text { Sub-area, Candor } 1235 \text { only } \\
\text { must be added to timing of V.1 }\end{array}$ \\
\hline
\end{tabular}

Refer to Table 1 for size of individual areas and to Table 4 for employed DTM resolution.

However, the choice of an appropriate DTM resolution was a task within the test itself. Therefore, results are not related to the number of DTM posts but to the size of the processed area. In order to have an idea of the number of DTM posts processed, the DLR-Scholten DTM with a grid size of $200 \mathrm{~m}$ resulted in approximately 12.6 million points. The times do not necessarily give a true reflection of the computational requirements of the DTM generation procedure, and in particular the matching approach as such. Also, one has to keep in mind that according to current experience the need for additional test runs for many orbits cannot be anticipated prior to starting the work. This is particularly important if highest accuracy and finest detail is a prime requirement. Nevertheless, clear differences can be made out. Not surprisingly, the results with the best operational performance were the DLR contributions offering extensive experience in processing HRSC data. 


\section{Conclusions}

Overall the test was very successful and has demonstrated that a number of methods exist, which are able to generate high quality DTMs from HRSC imagery. Nevertheless, noticeable differences in the participants' results were found. Some approaches yield superior results, not surprisingly these are the approaches which were developed with planetary imagery in mind, and those which have been extensively applied to planetary and in particular to HRSC image data in the past. While DLR-Scholten and DLRHirschmüller turned out to be the most operational methods in terms of processing time (per orbit only few hours are needed), the approaches of DLR-Gwinner and DLR-Gwinner/IPF yielded the best overall results in terms of accuracy and fine detail, still providing operational production times with only a few days processing per orbit. The DLR-Scholten/UniBwM and the USGS V.2 solutions, which refine a matching result by SFS, also resulted in remarkable improvement in visual detail, although no improvement in absolute heights is achieved. Furthermore, the test confirms previous findings that the DTMs generated from HRSC data, at least at lower latitudes, are clearly superior to the MOLA MEGDR in terms of resolution and visible fine detail. Very detailed DTMs can be generated from the HRSC images; at least in some areas it appears to be feasible to produce a DTM with a grid size of two to three times the resolution of the nadir image.

The geometric accuracy of the derived DTMs varies with terrain characteristics (undulation, texture, etc.). As measured against MOLA tracks a standard deviation of approximately $20 \mathrm{~m}$ in height (which corresponds to a ground resolution of one pixel) could be reached for the relatively flat Nanedi test site in the best case. For the more complex Candor Chasma image with a number of steep slopes, less image contrast and more radiometric noise, a standard deviation of two pixels was obtained in the best case. These results correspond to the values which are reached in aerial photogrammetry using image matching and can thus be classified as excellent taking into account the generally low texture of planetary images. While manual editing is known to be able to improve the results particularly with respect to blunder elimination, the test did not focus on evaluating this aspect. Given the sheer amount of data in planetary missions, manual mapping is very costly, and automation is thus the only realistic way to produce results with a reasonable amount of resources. Nevertheless, some manual elimination of blunders may be necessary to achieve highest standards for DTM accuracy, but cost-effectiveness requires that this step be minimised by optimising the performance of the automated matching.

Some inferences can be made for further developments of the matching algorithms: (a) the use of multiple images instead of only the nadir and the two stereo channels often improves the results, (b) the reduction of radiometric noise prior to image matching appears to carry a lot of promise (see also Gwinner et al., 2005; Schmidt et al., 2006), (c) rectifying the images at least to a plane prior to matching is mandatory. More advantageous seems to be a rectification to a DTM such as the MOLA MEGDR or, even better, a DTM generated within the matching process, in particular in areas with steep slopes, (d) detecting and eliminating blunders must be seen as an essential sub-task at every step of the processing chain and (e) general purpose algorithms should be carefully adapted to the peculiarities of the HRSC sensor, e.g. the geometric sensor model, macro-pixel formats and varying integration time. It is interesting to note that, in cooperation with USGS, BAE System has already implemented some of these improvements into their commercial software (DeVenecia et al., 2007). We could also show that in order to generate consistent results a photogrammetric bundle adjustment approach is an important step. Control information is provided through the introduction of MOLA data, which also guarantees compatibility with this data set.

High resolution HRSC DTMs and orthoimages will be produced at DLR systematically from the whole data set. It is planned, that this archival data set, which is based on the DLR-Gwinner approach, will be archived in the Planetary Data System (PDS) starting at the end of 2007. Thus, this valuable asset of the HRSC experiment will soon be available to the wider Mars community.

\section{References}

Albertz, J., Attwenger, M., Barrett, J., Casley, S., Dorninger, P., Dorrer, E., Ebner, H., Gehrke, S., Giese, B., Gwinner, K., Heipke, C., Howington-Kraus, E., Kirk, R.L., Lehmann, H., Mayer, H., Muller, J.-P., Oberst, J., Ostrovskiy, A., Renter, J., Reznik, S., Schmidt, R., Scholten, F., Spiegel, M., Stilla, U., Wählisch, M., Neukum, G., the HRSC Co-Investigator Team, 2005. HRSC on Mars Expressphotogrammetric and cartographic research. Photogramm. Eng. Remote Sensing 71 (10), 1153-1166.

Attwenger, M., Neukum, G., the HRSC Co-Investigator Team, 2005. Klassifikation von HRSC-Objektpunkten zur Generierung hochwertiger Geländemodelle der Marsoberfläche. Photogramm. Fernerkundung Geoinf. 4 (5), 395-402.

Day, T., Cook, A.C., Muller, J.-P., 1992. Automated digital topographic mapping technique for Mars. Int. Arch. Photogramm. Remote Sensing 29 (B4), 801-808.

DeVenecia, K., Walker, S., Zhang, B., 2007. New approaches to generating and processing high resolution elevation dta with imagery. In: Fritsch, D. (Ed.), Photogrammetric Week '07, Wichmann, Heidelberg.

Dorrer, E., Mayer, H., Ostrovskiy, A., Reznik, S., Neukum, G., the HRSC Co-Investigator Team, 2004. De- and re-shading of Mars Express HRSC image data for homogenization of map relief shading. Int. Arch. Photogramm. Remote Sensing Spatial Inf. Sci. XXXV (Part B4), 1304-1308.

Dorrer, E., Mayer, H., Haase, Y., Ostrovskiy, A., Renter, J., Rentsch, M., Reznik, S., Neukum, G., the HRSC Co-Investigator Team, 2005. Verbesserung räumlicher Daten durch "Shape-from-Shading". Photogramm. Fernerkundung Geoinf. (5), 403-408.

Gehrke, S., Neukum, G., the HRSC Co-Investigator Team, 2005. Das kartographische Softwarepaket Planetary Image Mapper (PIMap). Photogramm. Fernerkundung Geoinf. (5), 417-422.

Grün, A., 1985. Adaptive least squares correlation: a powerful image matching technique. S. Afr. J. Photogramm. Remote Sensing Cartograph. 13 (3), 175-187. 
Gwinner, K., Scholten, F., Spiegel, M., Schmidt, R., Giese, B., Oberst, J., Jaumann, R., Neukum, G., the HRSC Co-Investigator Team, 2005. Hochauflösende Digitale Geländemodelle auf der Grundlage von Mars Express HRSC-Daten. Photogramm. Fernerkundung Geoinf. (5), 387-394.

Gwinner, K., Scholten, F., Jaumann, R., Roatsch, T., Oberst, J., Neukum, G., 2007. Global mapping of Mars by systematic derivation of Mars Express HRSC high-resolution digital elevation models and orthoimages. In: Proceedings of the ISPRS Working Group IV/7 Workshop, Houston, March 17, 2007, 3pp.

Hirschmüller, H., 2005. Accurate and efficient stereo processing by semiglobal matching and mutual information. In: Proceedings of the IEEE Conference on Computer Vision and Pattern Recognition, 20-26 June 2005, San Diego, CA, USA, vol. 2, pp. 807-814.

Hirschmüller, H., Scholten, F., Hirzinger, G., 2005. Stereo vision based reconstruction of huge urban areas from an airborne push broom camera (HRSC). In: Lecture Notes in Computer Science: Pattern Recognition, Proceedings of the 27th DAGM Symposium, pp. 58-66.

Hirschmüller, H., Mayer, H., Neukum, G., the HRSC Co-Investigator Team, 2006. Stereo processing of HRSC Mars Express images by semiglobal matching. Int. Arch. Photogramm. Remote Sensing Spatial Inf. Sci. XXXVI (Part 4A), 305-310.

Kim, J.R., 2005. Landscape object detection and reconstruction by multisensor data fusion. Ph.D. Thesis, University College London, $412 \mathrm{pp}$.

Kirk, R.L., Howington-Kraus, E., Redding, B., Galuszka, D., Hare, T.M., Archinal, B.A., Soderblom, L.A., Barrett, J.M., 2003. Highresolution topomapping of candidate MER landing sites with Mars Orbiter Camera Narrow-Angle images. J. Geophys. Res. 108 (E12), 8088.

Kirk, R.L., Howington-Kraus, E., Galuszka, D., Redding, B., Hare, T.M., 2006. Topomapping of Mars with HRSC Images, ISIS, and a Commercial Stereo Workstation. Int. Arch. Photogramm. Remote Sensing Spatial Inf. Sci. XXXVI (Part 4A), 293-298.

Miller, S.B., Walker, A.S., 1993. Further developments of Leica digital photogrammetric systems by Helava. In: ACSM/ASPRS Annual Convention and Exposition Technical Papers, vol. 3, pp. 256-263.

Miller, S.B., Walker, A.S., 1995. Die Entwicklung der digitalen photogrammetrischen Systeme von Leica und Helava. Z. Photogramm. Fernerkundung 63 (1), 4-16.

Neukum, G., Jaumann, R., the HRSC Co-Investigator Team, 2004. HRSC: The High Resolution Stereo Camera of Mars Express. ESA Special Publications SP-1240.

Neumann, G.A., Lemoine, F.G., Smith, D.E., Zuber, M.T., 2003. The Mars Obiter Laser Altimeter archive: final precision experiment data record release and status of radiometry. In: Lunar Planetary Science, vol. XXXIV. Lunar and Planetary Institute, Houston.
Otto, G.P., Chau, T.K.W., 1989. Region-growing algorithm for matching of terrain images. Image Vis. Comput. 7, 83-94.

Rengarajan, R., Yoon, J.-S., Shan, J., 2004. Triangulation based hierarchical image matching for Mars DEM generation using MOC NA stereo images. In: Proceedings of the Annual Convention of the ASPRS, 12pp. (on CD-ROM).

Schmidt, R., Heipke, C., Brandt, R., Neukum, G., the HRSC CoInvestigator Team, 2005. Automatische Bestimmung von Verknüpfungspunkten in HRSC-Bildern der Mars Express Mission. Photogramm. Fernerkundung Geoinf. (5), 373-379.

Schmidt, R., Heipke, C., Neukum, G., the HRSC Co-Investigator Team, 2006. Improving tie point extraction by anisotropic diffusion. Int. Arch. Photogramm. Remote Sensing Spatial Inf. Sci. XXXVI (Part 4A), 352-357.

Scholten, F., Gwinner, K., Roatsch, T., Matz, K.-D., Wählisch, M., Giese, B., Oberst, J., Jaumann, R., Neukum, G., the HRSC CoInvestigator Team, 2005. Mars Express HRSC data processingmethods and operational Aspects. Photogramm. Eng. Remote Sensing $71(10), 1143-1152$.

Scholten, F., Roatsch, T., Gwinner, K., Matz, K.-D., Mertens, V., Flohrer, J., Wählisch, M., Giese, B., Pischel, R., Oberst, J., Jaumann, R., Neukum, G., the HRSC Co-Investigator Team, 2005. Von Rohdaten aus dem Mars Express Orbit zu Digitalen Marsoberflächenmodellen und Orthobildern - Operationelle Verarbeitung von HRSC Daten. Photogramm. Fernerkundung Geoinf. (5), 365-372.

Shepard, M.K., et al., 2001. The roughness of natural terrain: a planetary and remote sensing perspective. J. Geophys. Res. 106 (E12), 32,777-32,795.

Smith, D.E., Zuber, M.T., Frey, H.V., Garvin, J.B., Head, J.W., Muhleman, D.O., Pettengill, G.H., Phillips, R.J., Solomon, S.C., Zwally, H.J., Banerdt, W.B., Duxbury, T.C., Golombek, M.P., Lemoine, F.G., Neumann, G.A., Rowlands, D.D., Aharonson, O., Ford, P.G., Ivanov, A.B., Johnson, C.L., McGovern, P.J., Abshire, J.B., Afzal, R.S., Sun, X., 2001. Mars Orbiter Laser Altimeter: experiment summary after the first year of global mapping of Mars. J. Geophys. Res. 106 (E10), 23689-23722.

Spiegel, M., Stilla, U., Giese, B., Neukum, G., the HRSC Co-Investigator Team, 2005. Bündelausgleichung von HRSC Bilddaten mit Mars Observer Laser Altimeter-Daten als Passinformation. Photogramm. Fernerkundung Geoinf. (5), 381-386.

Spiegel, M., Stilla, U., Neukum, G., 2006. Improving the exterior orientation of Mars Express regarding different imaging cases. Int. Arch. Photogramm. Remote Sensing Spatial Inf. Sci. XXXVI (Part $4 \mathrm{~A}), 358-363$.

Zuber, M.T., Smith, D.E., Solomon, S.C., Muhleman, D.O., Head, J.W., Garvin, J.B., Abshire, J.B., Bufton, J.L., 1992. The Mars Observer Laser Altimeter Investigation. J. Geophys. Res. E5 (97), 7781-7797. 